\title{
A boundary element approach for the evaluation of SSI effects in presence of pile foundations under steady-state conditions
}

\author{
Roberto Cairo ${ }^{1}$ (D)
}

Received: 30 May 2021 / Accepted: 18 January 2022 / Published online: 6 February 2022

(c) The Author(s) 2022

\begin{abstract}
Simplified procedures, capable of predicting the main effects of soil-structure interaction (SSI), involving minimum computational effort are desired in engineering practice. Besides, user-friendly approaches can be incorporated into guidelines or practical recommended procedures. Nevertheless, approximate solutions need to be carefully validated through rigorous analytical or numerical methods, as well as by the comparison with experimental results or field measurements. In the case of piles, the flexibility of the soil-foundation system plays a fundamental role in structural design and the evaluation of the pile group effects still represents a crucial task in practical problem. In this paper, a Boundary Element approach based on the Stiffness Matrix Method (Kausel in Fundamental solutions in elastodynamics. A compendium, Cambridge University Press, England, 2006) is employed to investigate the key features of SSI, by comparison with the actual field data collected by Stewart et al. (Empirical evaluation of inertial soil-structure interaction effects. Rep. No. PEER-98/07, Pacific Earthquake Engineering Research Center, 1998) from instrumented sites and structures.
\end{abstract}

Keywords Piles $\cdot$ Shear wave velocity profile $\cdot$ Stiffness matrix method $\cdot$ Steady-state response $\cdot$ SDOF

\section{Introduction}

Although various phenomena are involved into a soil-structure interaction (SSI) problem (Kausel 2010), the principal aspects can be summarized in the following three issues (Gazetas 1987):

Roberto Cairo

rcairo@unical.it

1 Department of Civil Engineering, University of Calabria, 87036 Rende, CS, Italy 
(1) the flexibility of the soil-foundation system determines the decreasing of the fundamental frequency of vibration of the structure with respect to the fixed-base condition;

(2) the vibrational energy of the structure is dissipated into the supporting soil by radiation of waves to infinity and by the hysteretic behavior of the soil;

(3) the incident seismic waves are filtered by rigid deep foundations and the shaking motion transmitted to the structure is generally modified: the horizontal displacement is reduced with respect to the free-field ground motion; rocking and torsional components may also arise.

From a conceptual point of view, the first two aspects are referred to 'inertial' interaction, whereas the last one is indicated as 'kinematic'. The distinction in two separate types of interaction is very attractive and computationally efficient within the framework of the substructure method (Mylonakis et al. 2006).

Furthermore, owing to the passage of seismic waves into the surrounding soil, piles may suffer important deformations and bending ('kinematic') moments in the vicinity of interfaces of alternating soft and stiff soil layers (Gazetas and Mylonakis 1998).

As a matter of fact, among other structures and circumstances, Eurocode 8 (EN 1998-5 2005) states that SSI analyses shall be performed for structures founded on piles.

In general, it is recognized that SSI effects are most important at short periods of vibration (Stewart et al. 2004), where they tend to reduce the shaking demand on structures, decreasing the design values of the base shear, lateral forces and overturning moments (NEHRP 2015).

Nevertheless, well documented case histories (Mylonakis and Gazetas 2000) show important spectral amplification at somewhat high structural period as a result of resonance of the soft deep soil deposits involved, as well as shaking ground motion directivity.

Detailed numerical models (Chau et al. 2009; Hokmabadi et al. 2014) based on the Finite Element or the Distinct Element Methods permit to analyze in a single step the soilstructure system, taking into account material non linearities, heterogeneous soil profiles, irregular and deformable foundations. Nonetheless, a complete solution is hard to achieve in many practical cases and the results obtained often need to be evaluated with appropriate engineering judgment. Actually, a complete solution is impossible to achieve even with the most advanced and detailed numerical models as the uncertainties for the problem parameters, especially those relevant to the soil properties, even if test results are available, are always present.

The essential features of SSI can be fortunately captured by alternative approaches, such as the Boundary Element Method (Millan and Dominguez 2009; Padron et al. 2011), though working under the superposition law.

In engineering practice, simplified procedures (Dobry 2014) capable of predicting the main results of SSI analyses are very suitable for preliminary studies as these request minimum computational effort. Furthermore, easy to use approaches can be incorporated into guidelines or codes (NEHRP 2020).

Besides the numerous numerical and theoretical procedures available, in recent years experimental methods and laboratory studies broadened (Chau et al. 2009; Hokmabadi et al. 2014, 2015; Durante et al. 2016; Hussien et al. 2016). However, field measurements and recorded data from instrumented structures on piles are rare (Stewart et al. 1999b; Nikolaou et al. 2001; Kim and Stewart 2003).

A well-documented collection of seismic case history data has been reported by Stewart et al. (1998). On 58 instrumented buildings sited in California, 77 strong motion events 
occurred from 1975 to 1994 were recorded. The structures were monitored with lateral sensors located at the foundation and roof levels. In 13 of these, vertical sensors at the footings were also arranged to detect base rocking. Free-field accelerographs were also placed in 45 of these sites. The base of the buildings consisted of both shallow and deep foundations. Fourteen of these structures were founded on piles.

The area included in the study was located besides the coast of California, starting from the Humboldt County, on the far North Coast in the north of San Francisco, reaching to Imperial Valley in Southern California.

The physical characteristics of the soils are reported for all the sites in examination (Stewart and Stewart 1997). For 29 soil deposits, the shear wave velocity $V_{\mathrm{s}}$ was measured in situ by geophysical tests. In the other cases, $V_{\mathrm{s}}$ profiles were calculated using empirical correlations.

The strong motion recordings were used to estimate the main modal structural parameters (frequency of vibration and damping ratio), using appropriate System Identification Analyses (SIA). The principal procedure adopted was based on the derivation of transfer functions, defined in the discrete time domain, between the recorded input motion and the recorded structural response. As known, transfer functions depend on the dynamic properties of the structures, considered with both fixed and flexible base. A second approach made use of transmissibility functions obtained through the ratio of the Fourier transform of the output and input recorded signals, that permit to identify the vibration frequencies at which amplification or de-amplification occurs. The basic rules of the two methods are described in details in Stewart et al. (1998).

The actual structure was represented by a generalized single-degree-of-freedom system (SDOF). The evaluation of the natural vibration frequency and the damping ratio, for various cases of base fixity, allowed to characterize the effects of SSI. Stewart et al. (1999a) used the results obtained via SIA to calibrate simplified analytical procedures available in the literature.

Generally, these approaches are not adequate for incorporating pile group effects in both foundation stiffness and damping. In this case, the development of design methods is still hard to be achieved (Maravas et al. 2014).

In the present work, a linear but theoretically robust boundary element approach is employed to investigate the key features of SSI. The case studies collected by Stewart et al. (1998) from instrumented sites and structures are used for comparisons. Although under steady-state conditions, the analyses performed reveal capable to identify the cases in which the SSI effects are important.

\section{Outline of the method used}

The approach herein addressed is based on the Stiffness Matrix Method originally developed by Kausel and Röesset (1981) to simulate the dynamic response of layered soils. The framework of this approach was previously derived by Cairo et al. (2005), and Cairo and Conte (2006) for the analysis of vertically loaded pile groups under dynamic and static conditions. Recently, Cairo et al. (2020) expanded on the method to account different modes of loading, including seismic waves propagation.

The problem considered consists of a group of vertical piles embedded in a layered soil (Fig. 1). Each layer is modelled as an elastic material of Young's modulus $E_{\mathrm{s}}$, 
Fig. 1 Pile group in a layered soil

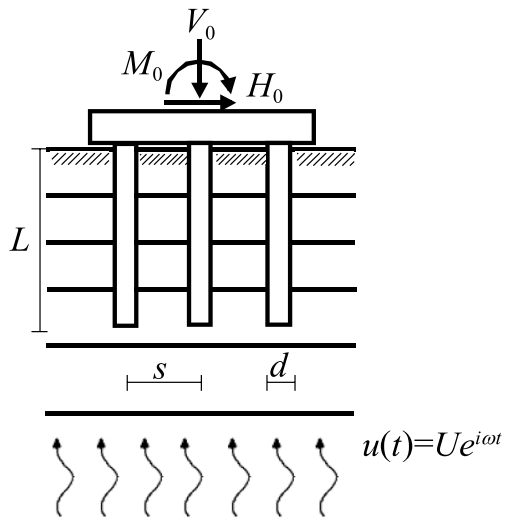

Poisson's ratio $\nu_{\mathrm{s}}$, mass density $\rho_{\mathrm{s}}$, and damping ratio $\beta_{\mathrm{s}}$. Each pile is considered to be an elastic cylinder of length $L$, diameter $d$, Young's modulus $E_{\mathrm{p}}$, and mass density $\rho_{\mathrm{p}}$.

The soil-pile system is assumed to be under steady-state harmonic oscillations, therefore any time-dependent variable is in general expressed as a complex quantity multiplied by the factor $e^{i \omega t}$, being $i=\sqrt{-1}, \omega$ the vibration circular frequency, and $t$ the time. In the following, this factor will be omitted for the sake of brevity, since it is shared by all time-dependent variables.

The solution procedure for the analysis of pile groups subjected to an external loading system $V_{0}, H_{0}, M_{0}$ is described first.

The problem can be split into two parts (Fig. 2): the piles subjected to external loads $\{P\}$ and soil-pile interaction forces $\left\{P_{p}\right\}$; the soil deposit that is subjected to the interaction forces $\left\{P_{s}\right\}$ at the pile-soil interfaces. The piles are subdivided into a finite number of one-dimensional elements, and the soil is replaced by a horizontally layered continuum. The nodes are the middle points of the elements and the central end points.

These two systems are first considered separately and then reassembled enforcing equilibrium of the internal pile-soil forces and compatibility of the pile and soil displacements at the pile-soil interfaces. It is worth noting that the difference in the number

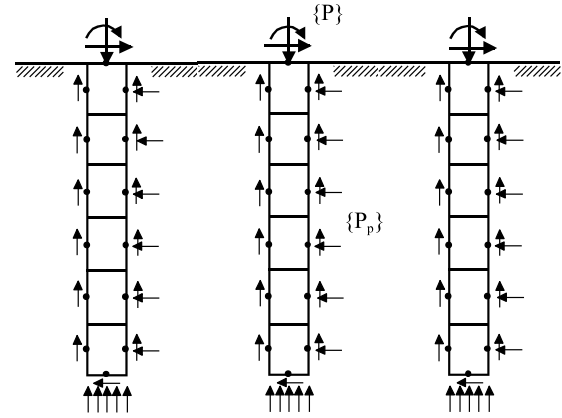

(a)

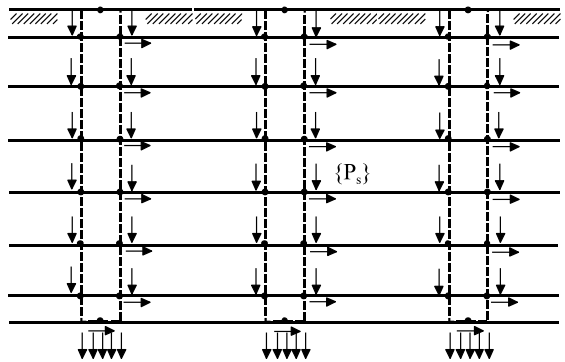

(b)

Fig. 2 Schematic analysis of a pile group: a loads acting on the piles; $\mathbf{b}$ loads acting on the soil at the pilesoil interfaces 
of degrees of freedom between the piles and the soil has to be accounted for, as pointed out in the following.

Under the above assumptions, the dynamic equilibrium equation for the group is given in matrix form as

$$
\left(\left[K_{p}\right]+\left[K_{s}\right]-\omega^{2}\left[M_{p}\right]\right)\left\{u_{p}\right\}=\{P\}
$$

where $\left[K_{p}\right]$ and $\left[M_{p}\right]$ are the assembled stiffness and mass matrices of the pile group, respectively; $\left[K_{s}\right]$ is the global stiffness matrix of the layered soil deposit; $\left\{u_{p}\right\}$ is the vector containing the displacements (vertical and horizontal) and rotations of pile nodes; $\{P\}$ the external pile forces.

Matrices $\left[K_{p}\right]$ and $\left[M_{p}\right]$ are determined using standard procedures of the structural analysis (Bhatti 2005). The salient feature of the present approach is the evaluation of $\left[K_{s}\right]$, which employs the Stiffness Matrix Method (Kausel 2006) as described in the following.

The soil domain is formed by a series of homogeneous and isotropic layers underlain by a homogeneous half-space. For each frequency $\omega$ and wavenumber $k$, the stiffness matrices of the layers and that of the half-space are determined and assembled in the stiffness matrix $[K]$ of the complete system. The terms of these matrices are complex and depend on the soil elastic properties and layer thickness. Damping is considered through complex elastic moduli.

The external forces are assumed to be applied in the form of tractions at the layer interfaces and need to be transformed from the space-time domain into the frequency-wavenumber domain. Adopting a cylindrical coordinates system, the soil-pile interaction forces are considered as ring loads applied to each element of the interfaces and disk loads uniformly distributed on the pile tips (Kausel 1981). The Hankel transforms of these forces in the wavenumber domain are available in closed form (Wolf 1985). Only the horizontal and vertical components of the loading are considered in this work. The rocking component is neglected, since it weakens rapidly with distance and does not contribute to pile-soil interaction. This is consistent with previous studies (Dobry and Gazetas 1988).

The transformed forces $\{p\}$ with unit amplitude, are applied one at a time on the pile nodes, and the corresponding radial, tangential and vertical displacements $\{\bar{u}\}$ are calculated by solving a standard system of equations as

$$
\{p\}=[K]\{\bar{u}\}
$$

For each harmonic component, the achieved transformed displacements (influence coefficients) at a given depth $z$ are discrete functions of $k$. The actual displacements are then calculated as a function of the radial distance $r$ from the pile axis and the azimuth $\theta$, using the inverse Hankel transforms.

In the case of vertical force, the following equations have to be used (Kausel 1981; Wolf 1985)

$$
\begin{aligned}
& u_{v}(r)=\int_{0}^{\infty} k J_{1}(k r) \bar{u}_{v}(k) d k \\
& w_{v}(r)=\int_{0}^{\infty} k J_{0}(k r) \bar{w}_{v}(k) d k
\end{aligned}
$$


where $u_{v}(r)$ and $w_{v}(r)$ are the radial and vertical displacements, respectively; $\bar{u}_{v}(k)$ and $\bar{w}_{v}(k)$ are the radial and vertical transformed displacements, respectively, obtained using Eq. (2); $J_{0}(k r)$ and $J_{1}(k r)$ are the Bessel functions of the first kind and order 0 and 1, respectively.

For the horizontal interaction force, the corresponding displacements are given as (Kausel 1981; Wolf 1985)

$$
\begin{gathered}
u_{h}(r, \theta)=\frac{\cos \theta}{2} \int_{0}^{\infty} k\left\{\left[J_{0}(k r)-J_{2}(k r)\right] \bar{u}_{h}(k)+\left[J_{0}(k r)+J_{2}(k r)\right] \bar{v}_{h}(k)\right\} d k \\
v_{h}(r, \theta)=-\frac{\sin \theta}{2} \int_{0}^{\infty} k\left\{\left[J_{0}(k r)+J_{2}(k r)\right] \bar{u}_{h}(k)+\left[J_{0}(k r)-J_{2}(k r)\right] \bar{v}_{h}(k)\right\} d k \\
w_{h}(r, \theta)=-\cos \theta \int_{0}^{\infty} k J_{1}(k r) \bar{w}_{h}(k) d k
\end{gathered}
$$

in which $u_{h}(r, \theta), v_{h}(r, \theta)$ and $w_{h}(r, \theta)$ are the actual radial, tangential and vertical displacements, respectively; $\bar{u}_{h}(k), \bar{v}_{h}(k)$ and $\bar{w}_{h}(k)$ are the corresponding transformed displacements in the wavenumber domain; $J_{0}(k r), J_{1}(k r)$ and $J_{2}(k r)$ are the Bessel functions of the first kind and order 0,1 and 2, respectively. The horizontal displacements in Cartesian coordinates can be easily computed.

The soil influence matrix of the entire pile group is thus constructed and then inverted to obtain the matrix $\left[K_{s}\right]$ of Eq. (1).

Equations (3) and (4) need to be solved by numerical integration, provided that an appropriate interval of discretization $\Delta k$ and an upper limit of integration $k_{\max }$ are adopted. As a matter of fact, the plots of all the transformed displacements $\bar{u}(k), \bar{v}(k)$, $\bar{w}(k)$ exhibit pronounced peaks in the low range of wavenumber $\left(k \leq k_{\text {lim }}\right)$, and $\Delta k$ has to be small enough. In the high wavenumber range, these influence functions become sharper and attain rapidly zero, so that larger intervals of $\Delta k$ may be selected.

According to Kausel (2018), the following limits can be chosen for the entire soil deposit

$$
\begin{gathered}
k_{\lim } \leq \frac{\omega}{V_{s_{\min }}} \\
k_{\max }=\max \left\{\left[\begin{array}{c}
\left.\left(\frac{3 \pi}{2 h_{\min }}\right)^{2}+\left(\frac{\omega}{V_{s_{\min }}}\right)^{2}\right]^{0.5} \\
2 k_{\mathrm{lim}}
\end{array}\right.\right.
\end{gathered}
$$

being $V_{s_{\min }}$ the minimum shear wave velocity and $h_{\min }$ the smallest thickness of the layers.

The pile group response is obtained by Eq. (1) adding the compatibility of displacements and rotations, and the equilibrium of interaction forces and moments between the pile heads and the cap. In this work, the case of a rigid fixed-head free-standing pile group is considered. As known, the foundation impedance matrix can be constructed by successively applying unit vertical and horizontal displacements and rotations to the pile cap.

The kinematic interaction analysis can be carried out in the same framework, considering that the total wave motion can be decoupled into two parts (Banerjee and Butterfield 1981): the free-field wave motion occurring in the soil in the absence of the piles, and the scattered 
Fig. 3 Displacements and rotations of a SDOF structure resting on soft soil

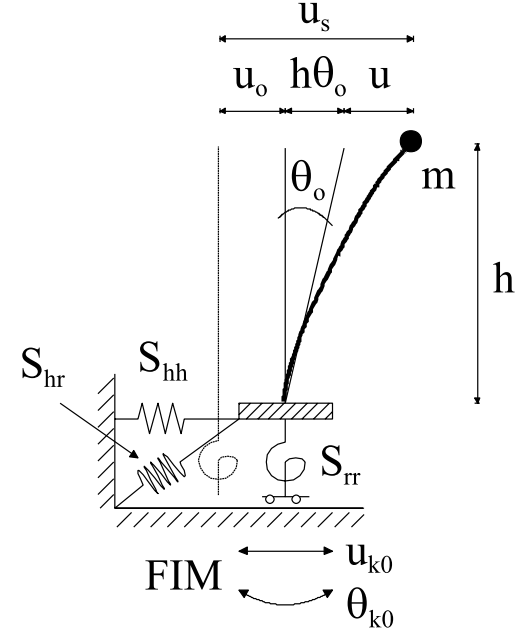

wave motion, consisting of the waves diffracted from the surface of the piles and propagating towards infinity. Equation (1) thus becomes (Cairo et al. 2020)

$$
\left(\left[K_{p}\right]+\left[K_{s}\right]-\omega^{2}\left[M_{p}\right]\right)\left\{u_{p}\right\}=\{P\}+\left[K_{s}\right]\left\{u_{\mathrm{ff}}\right\}-\left\{P_{\mathrm{ff}}\right\}
$$

being $\left\{u_{\mathrm{ff}}\right\}$ and $\left\{P_{\mathrm{ff}}\right\}$ the vectors containing the displacements and forces in the free-field soil system, respectively.

Prior to solving the complete dynamic equilibrium of the pile group, $\left\{u_{\mathrm{ff}}\right\}$ and $\left\{P_{\mathrm{ff}}\right\}$ need to be evaluated by a site response analysis performed within the same approach (Kausel 2006). The kinematic response of the group is thus achieved in terms of the translational $u_{k 0}$ and rotational $\theta_{k 0}$ components of the so-called foundation input motion (FIM).

In the final step, the inertial interaction is determined applying the FIM at the base of the structure in which the soil-foundation system is modelled with springs and dashpots (impedance matrix) associated to each mode of vibration.

The structures considered in the next section are simulated by a SDOF system (Fig. 3) with equivalent mass $m$ placed at a distance $h$ (effective height) from the base. The stiffness and damping of the SDOF are associated with the fundamental mode of vibration of the structure built in at its base. The dynamic stiffness of the pile foundation is represented by the horizontal impedance $S_{\mathrm{hh}}$, the rocking impedance $S_{\mathrm{rr}}$ and the coupled components $S_{\mathrm{hr}}=S_{\mathrm{rh}}$. The foundation has two degrees of freedom consisting of the horizontal displacement $u_{0}$, and the rocking $\theta_{0}$. The elastic horizontal displacement of the top mass relative to the base mass has amplitude $u$. The total displacement of the structure is deduced as $u_{s}=u+u_{0}+h \theta_{0}$.

Ignoring the mass of the pile cap and the mass moment of inertia of the structure and the foundation, the equations of motion of the system can be formulated as (Cairo et al. 2016)

$$
\left[\begin{array}{ccc}
-1+\frac{1+2 i \zeta}{\left(\omega / \omega_{\mathrm{fb}}\right)^{2}} & -1 & -1 \\
-1 & -1+\frac{S_{\mathrm{hh}}}{\omega^{2} m} & -1+\frac{S_{\mathrm{hr}}}{\omega^{2} m h} \\
-1 & -1+\frac{S_{\mathrm{rh}}}{\omega^{2} m h} & -1+\frac{S_{\mathrm{rr}}}{\omega^{2} m h^{2}}
\end{array}\right]\left\{\begin{array}{c}
u \\
u_{0} \\
h \theta_{0}
\end{array}\right\}=\left\{\begin{array}{l}
1 \\
1 \\
1
\end{array}\right\} u_{k 0}+\left\{\begin{array}{l}
1 \\
1 \\
1
\end{array}\right\} h \theta_{k 0}
$$

where $\omega_{\mathrm{fb}}$ is the natural circular frequency of the fixed-base structure, and $\zeta$ the damping ratio. 
Table 1 Data used for case studies

\begin{tabular}{|c|c|c|c|c|c|c|c|c|c|c|c|}
\hline Case & $\begin{array}{l}\text { PGA } \\
(\mathrm{g})\end{array}$ & $\begin{array}{l}L \\
(\mathrm{~m})\end{array}$ & $\begin{array}{l}d \\
(\mathrm{~m})\end{array}$ & $E_{\mathrm{p}} / \mathrm{E}_{\mathrm{s}}$ & $\begin{array}{l}\rho_{\mathrm{s}} \\
\left(\mathrm{Mg} / \mathrm{m}^{3}\right)\end{array}$ & $\nu_{\mathrm{s}}$ & $\begin{array}{l}\beta_{\mathrm{s}} \\
(\%)\end{array}$ & $\begin{array}{l}m \\
(\mathrm{Mg})\end{array}$ & $\begin{array}{l}h \\
(\mathrm{~m})\end{array}$ & $\begin{array}{l}f_{\mathrm{fb}} \\
(\mathrm{Hz})\end{array}$ & $\begin{array}{l}\zeta \\
(\%)\end{array}$ \\
\hline 1 & 0.24 & $14-18$ & 0.3 & 973 & 1.9 & 0.4 & 7.6 & 5500 & 17.8 & 2 & 23.4 \\
\hline 2 & - & 13.2 & 0.3 & 106 & 2.0 & 0.45 & 4.1 & 6850 & 18.3 & 3.49 & 18.6 \\
\hline 3 & 0.054 & 20 & 0.3 & 61 & - & 0.45 & 2.8 & 6300 & 20.7 & 1.88 & 5.7 \\
\hline 4 & 0.10 & 10 & 0.6 & 98 & 1.9 & 0.33 & 3.4 & 8400 & 22.2 & 0.50 & 6.8 \\
\hline 5 & 0.25 & 15 & 0.8 & 116 & 2.0 & 0.45 & 8.0 & 128,500 & 23.4 & 1.09 & 9.3 \\
\hline 6 & 0.086 & 15 & 0.4 & 115 & - & 0.45 & 4.1 & 6500 & 16.8 & 1.49 & 7.5 \\
\hline 7 & 0.26 & 30 & 0.35 & 285 & - & 0.45 & 8.4 & 28,200 & 66.6 & 0.41 & 7.4 \\
\hline 8 & 0.07 & 12 & 0.4 & 150 & - & 0.33 & 3.5 & 7000 & 17.4 & 0.88 & 6.5 \\
\hline 9 & 0.28 & 22 & - & 480 & 2.0 & 0.45 & 9.2 & 47,000 & 66 & 0.29 & - \\
\hline 10 & - & 60 & 0.4 & 432 & 1.9 & 0.45 & 4.3 & 70,000 & 124 & 0.20 & - \\
\hline 11 & 0.04 & 10 & 0.375 & 82 & - & 0.45 & 2.4 & 15,000 & 11.4 & 1.10 & 4.0 \\
\hline 12 & 0.39 & $4-9$ & 0.4 & 85 & 1.92 & 0.40 & 10 & 8000 & 28.8 & 1.34 & 8.5 \\
\hline 13 & 0.21 & 10 & 0.6 & 67 & 1.88 & 0.33 & 6.4 & 2300 & 8.4 & 3.50 & 4.9 \\
\hline 14 & 0.23 & $8.6-11.6$ & 0.4 & 131 & 1.8 & 0.40 & 7.2 & 14,400 & 21 & 0.65 & 8.5 \\
\hline
\end{tabular}

\section{Case studies}

All the cases examined in the following paragraphs are summarized in Table 1, in which the fundamental parameters used are listed. Further indications are given in the text.

\subsection{Case study 1: Imperial County Service Building, El Centro}

The first case examined concerns the Imperial County Service Building in El Centro. It was severely damaged during the 1979 Imperial Valley Earthquake (Arnold et al. 1982), subsequently demolished and replaced in 1981. The study refers to the original six story reinforced concrete structure (Shepherd and Plunkett 1983; Kojic et al. 1993), $25.48 \mathrm{~m}$ in height, $41.7 \mathrm{~m}$ by $26 \mathrm{~m}$ in plan (Fig. 4a), founded on 216 Raymond step tapered concrete piles interconnected by tie beams. The piles extended $14 \mathrm{~m}$ to $18 \mathrm{~m}$ into the soil deposit, which consisted of $120 \mathrm{~m}$ deep interbedded silty clays and sands. The shear wave velocity profile based on downhole measurements is shown in Fig. 4b.

Recorded time histories refer to the 1979 Imperial Valley earthquake, characterized by magnitude $M_{w}=6.5$ and free-field peak horizontal acceleration $0.24 \mathrm{~g}$. Stewart and Stewart (1997) estimated the fundamental frequency of the soil deposit in the range $0.7-0.8 \mathrm{~Hz}$.

In the present study, the measured shear wave velocity is reduced appropriately in the first $20 \mathrm{~m}$ of depth, to take into account the strain level induced by the earthquake motion into the subsoil. This is consistent with the suggestions provided by EC8 and favorably applied by Cairo et al. (2009). In the absence of specific data, the reduction factor of $V_{\mathrm{s}}$ is selected as a function of the peak ground acceleration recorded (Table 2).

For the surface softer layer of thickness $4.8 \mathrm{~m}$ a reduction factor of 0.51 is adopted, whereas a factor of 0.81 is used for the underlying layer. Similarly, a soil damping ratio $\beta_{\mathrm{s}}$ of $7.6 \%$ is assumed. 
Fig. 4 Imperial County Service Building: a foundation plan; b shear wave velocity profile (adapted from Stewart and Stewart 1997)
Table 2 Average soil damping and average reduction factor for shear wave velocity as a function of the peak ground acceleration (EN 1998-5 2005) (a)
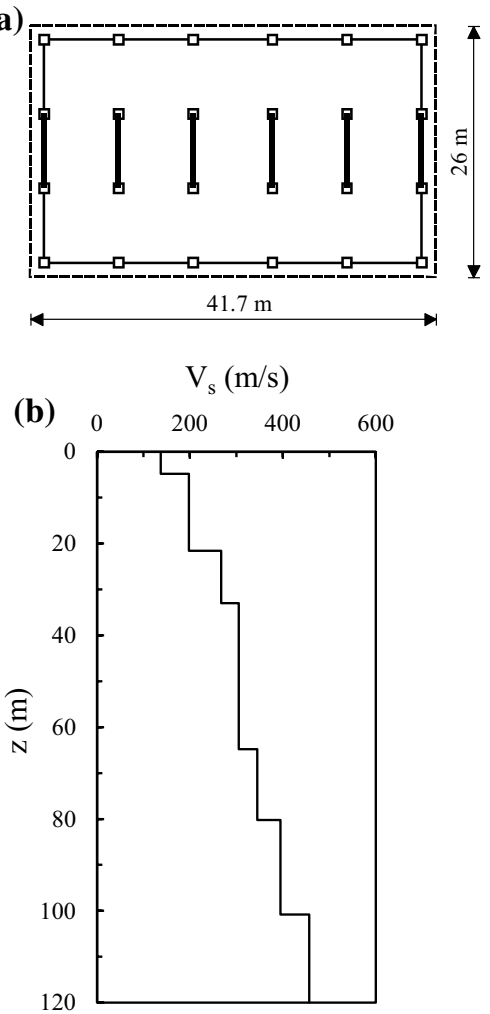

\begin{tabular}{lcl}
\hline PGA $(\mathrm{g})$ & $\beta_{\mathrm{s}}(\%)$ & $V_{\mathrm{s}} / V_{\mathrm{s}, \max }$ \\
\hline 0.10 & 3 & $0.90( \pm 0.07)$ \\
0.20 & 6 & $0.70( \pm 0.15)$ \\
0.30 & 10 & $0.60( \pm 0.15)$ \\
\hline
\end{tabular}

Values of $V_{\mathrm{s}} / V_{\mathrm{s}, \max }$ above the average could be used for stiffer profile, and values below the average for softer profile

According to Stewart et al. (1999b), the effective height $h$ of the generalized SDOF can be calculated roughly as 0.7 times the total height of the structure. The equivalent mass $m$ can be obtained from the mass parameter $\gamma=m /\left(\rho_{s} A_{b} h\right) \approx 0.15$ (Stewart et al. 1999a), being $A_{b}$ the area of the actual foundation. All the specific values assumed are listed in Table 1.

Firstly, the kinematic response of the pile group is described in terms of the kinematic factors

$$
I_{u}=\frac{u_{k 0}}{u_{\mathrm{ff}}}
$$



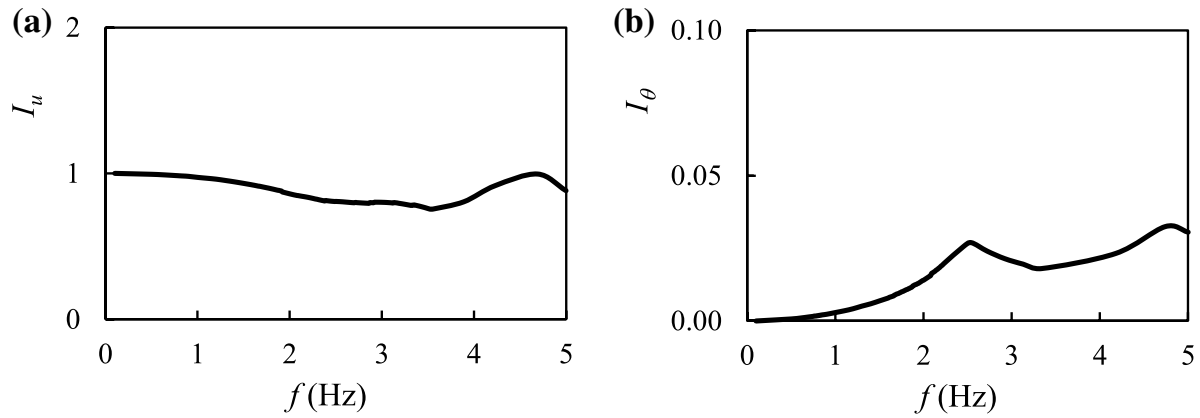

Fig. 5 Kinematic interaction factors of the pile foundation of the Imperial County Service Building

$$
I_{\theta}=\frac{\theta_{k 0} B}{u_{\mathrm{ff}}}
$$

being $u_{\mathrm{ff}}$ the horizontal free-field motion at the ground surface, and $B$ the width of the base. All the displacements and rotations are complex numbers, so that their amplitudes (absolute values) have to be used in the definition of the kinematic response factors. The trend of $I_{u}$ and $I_{\theta}$ as a function of frequency is reproduced in Fig. 5.

At very low frequency, the pile cap follows closely the free-field soil motion (Fig. 5a). With increasing frequency, the horizontal kinematic factor decreases as a consequence of the incompatibility between the wave motion into the soil and the displacement of the rigid pile foundation. At a relatively high frequency, $I_{u}$ becomes to fluctuate. The present result is in agreement with the extensive numerical study provided by Fan et al. (1991).

As known, the seismic interaction among the piles is generally negligible in the frequency range of interest (Gazetas et al. 1992). Therefore, the most important parameters affecting the kinematic response of piles are the relative rigidity $E_{\mathrm{p}} / E_{\mathrm{s}}$, heterogeneity of the soil, pile-head fixity conditions. In the case examined, the ratio $E_{\mathrm{p}} / E_{\mathrm{s} 1}=973$ is calculated with respect to the surface layer of the deposit and it is strong enough to reduce the horizontal kinematic factor in the intermediate-high frequency range. Furthermore, the rocking component of the FIM is scarcely significant (Fig. 5b). This can be ascribed to the relative high stiffness contrast $\left(V_{\mathrm{s} 2} / V_{\mathrm{s} 1}=2.3\right)$ between the upper and the lower layers around the deep foundation (Cairo and Conte 2014).

In Fig. 6, the harmonic steady-state response (amplification function) of the structural system to the applied foundation input motion is shown as a function of frequency $f$.

In particular, the amplitude of the total displacement $u_{\mathrm{s}}$ of the structure, normalized with the free-field ground motion $u_{\mathrm{ff}}$, is depicted with a red line and compared to the fixedbase displacement $u_{\mathrm{fb}}$ (black line). As can be noted, the peak response of the coupled soilstructure system occurs at a smaller resonant frequency $\left(f_{\text {sy }}=1.59 \mathrm{~Hz}\right)$, as it corresponds to a more flexible system. The value provided by Stewart et al. (1999b) is $1.35 \mathrm{~Hz}$. This discrepancy is probably due to a more pronounced nonlinear behavior of the soil. Besides, the calculated natural frequency $f_{\mathrm{ff}}=0.82 \mathrm{~Hz}$ of the soil deposit is indicated with an asterisk, and it proves to be slightly greater than the range estimated by Stewart and Stewart (1997).

The damping ratio $\zeta_{\text {sy }}$ of the overall system can be determined from the same amplification function by the half-power bandwidth method (Seybert 1981). A value of 17.5\% 


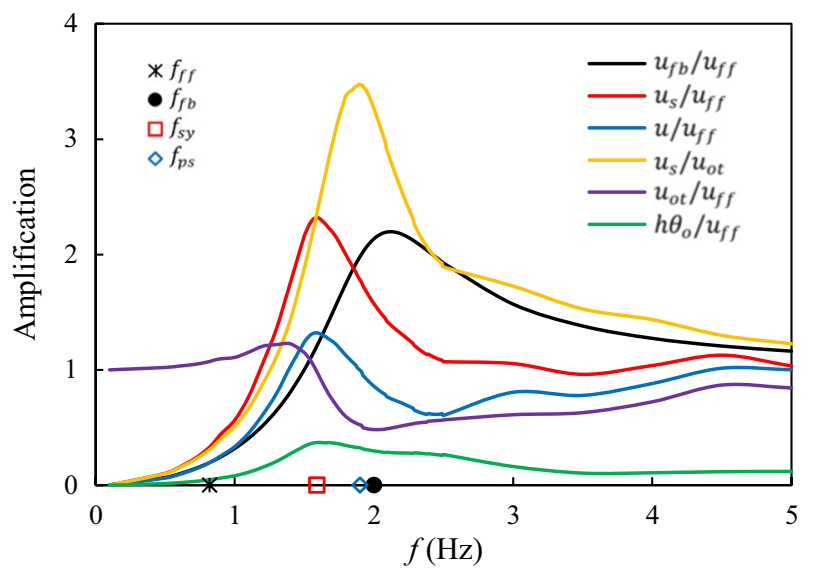

Fig. 6 Amplification functions of the SDOF system considered in case study 1

is evaluated, which is reduced with respect to the fixed-base damping $\zeta$, and compares favorably with the effective damping (16\%) observed by Stewart et al. (1999b).

The normalized elastic displacement $u$ of the structure is also indicated with a blue line. It should be noted that this important response quantity is somewhat smaller than the total structural displacement, and that a significant contribution to the peak response of the structure is likely due to the normalized rocking component $h \theta_{0}$ (green line) exhibited by its base. The same conclusion was deduced with the System Identification Analysis processed by Stewart and Stewart (1997), which explained the remarkable peak acceleration $(0.56 \mathrm{~g})$ experienced by the structure at the roof level with respect to the ground floor.

Finally, the so-called pseudo-natural frequency $f_{\mathrm{ps}}$ (Rovithis et al. 2009) of the system is shown (Fig. 6). It corresponds to the frequency in which the ratio of the amplitude $u_{\mathrm{s}}$ of the motion of the structure is maximized with respect to the amplitude of the total base motion $u_{0 t}=u_{0}+u_{k 0}$. This curve is plotted with a golden line. As can be observed, at this frequency the total base motion $u_{0 t}$ is further minimized relative to the free-field $u_{f f}$ (purple line).

A last remark can be drawn applying the free-field ground motion directly at the flexiblebase of the structure instead of FIM (i.e. neglecting kinematic interaction). The comparison reported in Fig. 7 demonstrates that the structural response becomes slightly higher, although the amplification curve broadens and the effective damping increases (18.8\%).

\subsection{Case study 2: 10-story Residential Building, San Jose}

The second case study refers to a ten-story reinforced concrete residential building (Fig. 8), sited in San Jose, subjected to the 1989 Loma Prieta earthquake $\left(M_{w}=6.9\right)$. The peak horizontal accelerations recorded at the base and roof of the structure was $0.12 \mathrm{~g}$ and $0.36 \mathrm{~g}$, respectively. No free-field accelerographs were available. The structure was rectangular in plan, founded on reinforced concrete piles, $13.2 \mathrm{~m}$ long and $300 \mathrm{~mm}$ square section. The generalized soil profile of the site is reported in Fig. 8c. The shear wave velocities were evaluated on the basis of empirical correlations. The bedrock was estimated at $450 \mathrm{~m}$. Stewart and Stewart (1997) suggested to adopt a reduction factor of 0.91 to the shear wave velocity within the first $30 \mathrm{~m}$ of depth and a soil damping $\beta_{\mathrm{s}}=4.1 \%$ to account for the amplitude accelerations induced by the earthquake. 


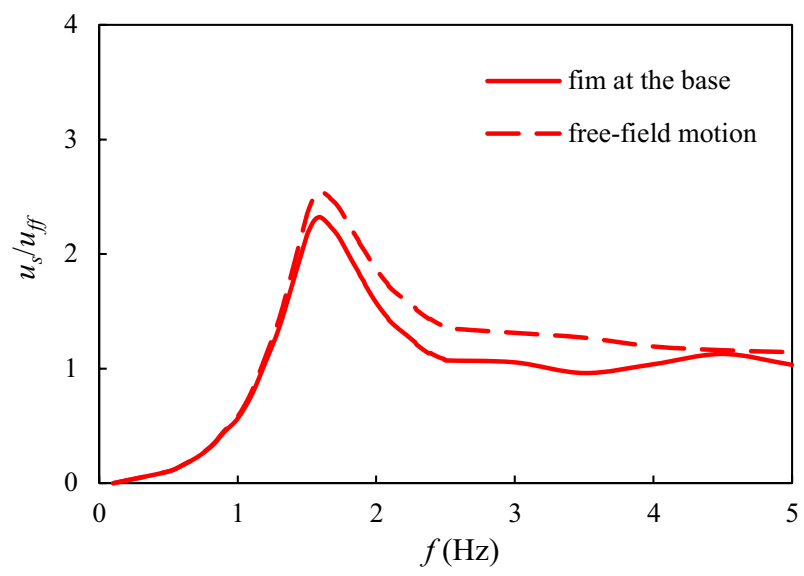

Fig. 7 Comparison between the response of the structure obtained applying FIM and free-field motion at its base (case study 1)

The amplification functions reported in Fig. 9 show important SSI effects on the dynamic response of the structure (red curve), as well as the system identification analysis performed by Stewart et al. (1999b) revealed. The natural frequency $f_{\text {sy }}$ of the complete system is equal to $2.09 \mathrm{~Hz}$ and the effective damping $\zeta_{\text {sy }}=8.4 \%$. These values are in good agreement with the observed results (Stewart et al. 1999b): $f_{\text {sy }}=2.08 \mathrm{~Hz}, \zeta_{\text {sy }}=6.7 \%$. The variation of ratio $h \theta_{0} / u_{\mathrm{ff}}$ (green curve) demonstrates the important contribution of base rocking on the total response of the structure and explains the great amplification of the seismic motion at the roof of the building (Stewart and Stewart 1997). The analyses carried out reveal a negligible kinematic interaction, being $E_{\mathrm{p}} / E_{\mathrm{s} 1}=106$.

\subsection{Case study 3: Ventura 12-story Hotel, Ventura}

The Ventura hotel is a 12-story building, with effective height $h=20.7 \mathrm{~m}$, fixed-base frequency $f_{\mathrm{fb}}=1.88 \mathrm{~Hz}$, damping ratio $\zeta=5.7 \%$. The foundation (Fig. 10a) consists of reinforced concrete Raymond tapered piles, $20 \mathrm{~m}$ long and with diameter $d=300 \mathrm{~mm}$. Beneath the lateral walls, the piles are installed in groups of 4 to 6 at a $3 d$ spacing; in the interior part, they are installed in two-pile groups. The heads of all the piles are cast into rigid caps, interconnected between columns by tie beams and a slab-on-grade floor. The soil profile is reported in Fig. 10b. The shear wave velocities were estimated based on correlations with void ratio and in situ down-hole measurements in similar soils near the hotel. Strong motion recordings refer to the 1994 Northridge earthquake with $M_{w}=6.7$ and $a_{\max }=0.054 \mathrm{~g}$ in the free-field site condition.

The calculated harmonic response of this structure (Fig. 10c) reveals a small interaction with the supporting soil $\left(f_{\mathrm{sy}}=1.76 \mathrm{~Hz}, \zeta_{\mathrm{sy}}=6 \%\right)$. The analyses conducted by Stewart et al. (1999b) demonstrated major inertial interaction effects $\left(f_{\text {sy }}=1.41 \mathrm{~Hz}, \zeta_{\text {sy }}=4 \%\right)$ and a significant contribution of base rocking to the response of the structure, which exhibited a peak horizontal acceleration of $0.25 \mathrm{~g}$ at the roof level. This discrepancy is likely due to the approximate evaluation of $V_{\mathrm{s}}$, which does not correspond to the actual stiffness of the soils where the foundation of the Ventura Hotel is embedded. 

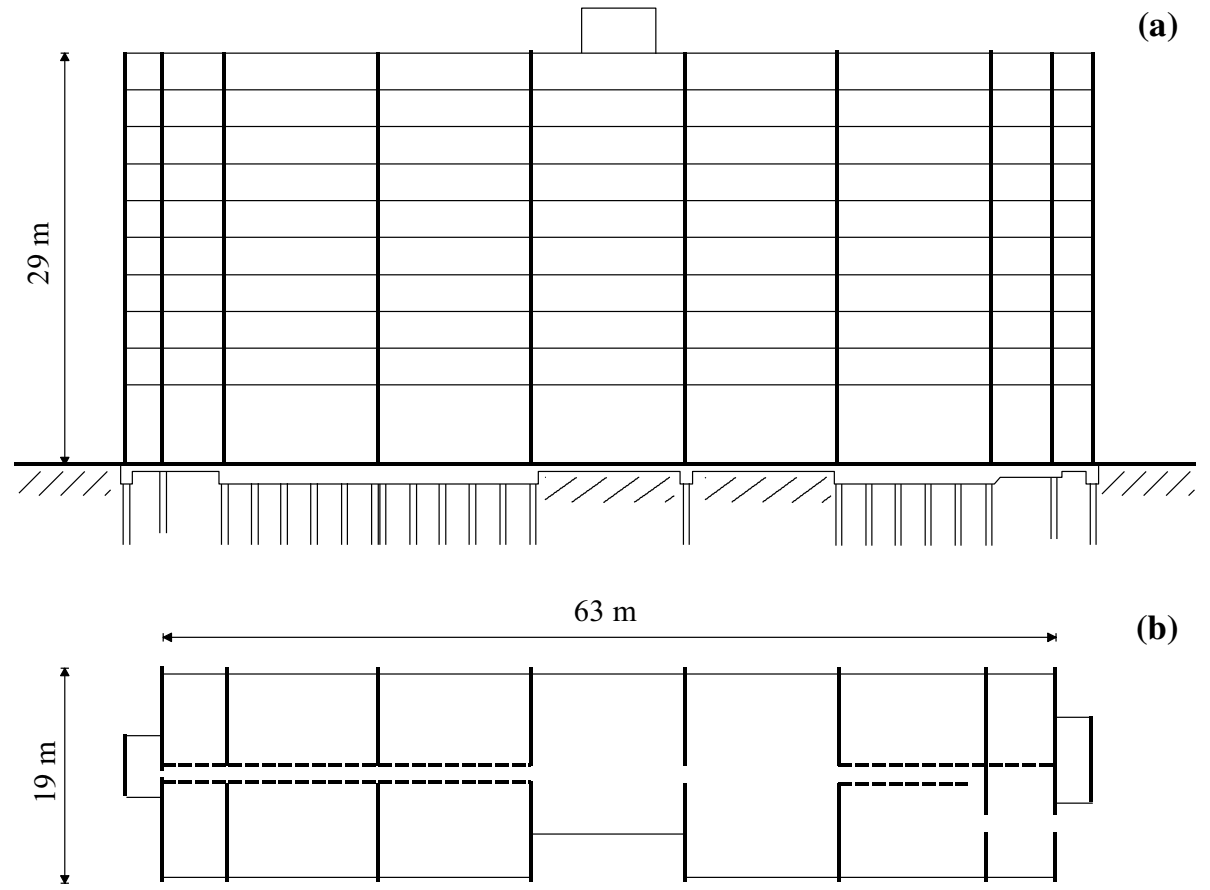

(b)

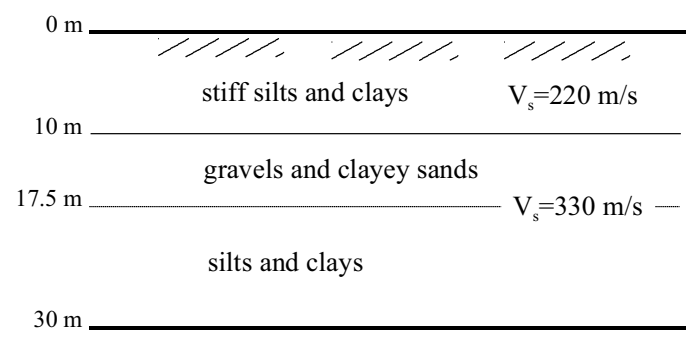

(c)

Fig. 8 Case 2-Residential Building (adapted from Stewart and Stewart 1997): a center section; b ground floor plan; c soil profile

\subsection{Case study 4: Vanir Tower, San Bernardino}

The Vanir Tower is a 9-story structure, $32 \mathrm{~m}$ high, sited in the San Bernardino Valley. Each column in the building (Fig. 11a) is founded on a group of four piles connected with a rigid cap. The pile caps are not tied together except for a tie beam around the building perimeter. The piles have length $10 \mathrm{~m}$ and diameter $600 \mathrm{~mm}$. Surficial young alluvial soils consist of $6 \mathrm{~m}$ of silts and clays, underlain by sands and gavels. At $45 \mathrm{~m}$ of depth, older alluvium deposits extend to a depth of $270 \mathrm{~m}$. The shear wave velocities shown in Fig. 11b were determined using correlations with void ratio and SPT blow count.

The structure was subjected to the 1992 Landers earthquake $\left(M_{w}=7.3\right)$. The recorded maximum free-field horizontal acceleration was $0.10 \mathrm{~g}$. According to this amplitude 


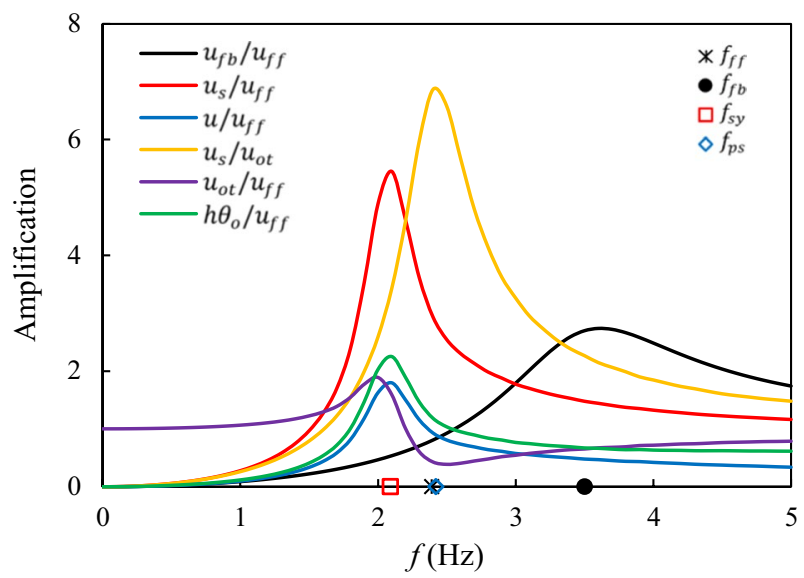

Fig. 9 Amplification functions of the equivalent SDOF residential structure (case 2)

(a)

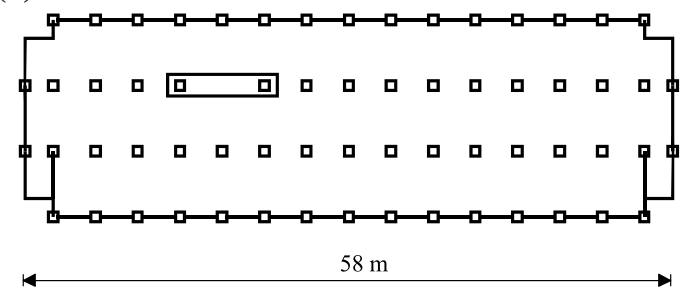

(c) 10

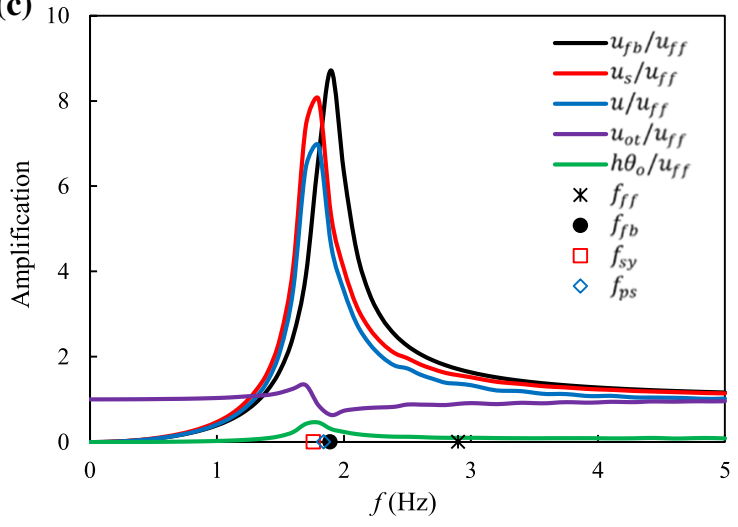

(b)
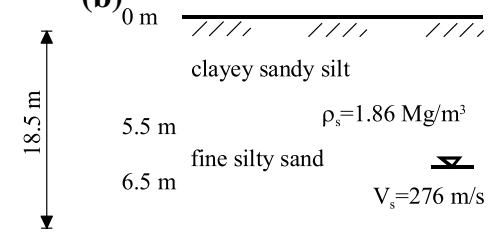

$5.5 \mathrm{~m}$

$\rho_{\mathrm{s}}=1.86 \mathrm{Mg} / \mathrm{m}^{3}$

$6.5 \mathrm{~m}$

fine silty sand

$\mathrm{V}_{\mathrm{s}}=276 \mathrm{~m} / \mathrm{s}$

silty clay

$\rho_{\mathrm{s}}=1.97 \mathrm{Mg} / \mathrm{m}^{3}$

$15 \mathrm{~m}$

interbedded $\quad \mathrm{V}_{\mathrm{s}}=420 \mathrm{~m} / \mathrm{s}$

silty clay and silty sand

$\rho_{\mathrm{s}}=2.07 \mathrm{Mg} / \mathrm{m}^{3}$

$24 \mathrm{~m}$

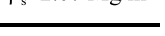

Fig. 10 Case 3-Ventura Hotel: a foundation plan (adapted from Stewart and Stewart 1997); b soil profile; c amplification functions

acceleration, soil damping $\beta_{\mathrm{s}}$ is set equal to $3.4 \%$ and a 0.925 reduction factor for $V_{\mathrm{s}}$ is used (Stewart and Stewart 1997).

The amplification functions displayed in Fig. 11c do not show any SSI effect as confirmed by the empirical findings reported by Stewart et al. (1999b). 

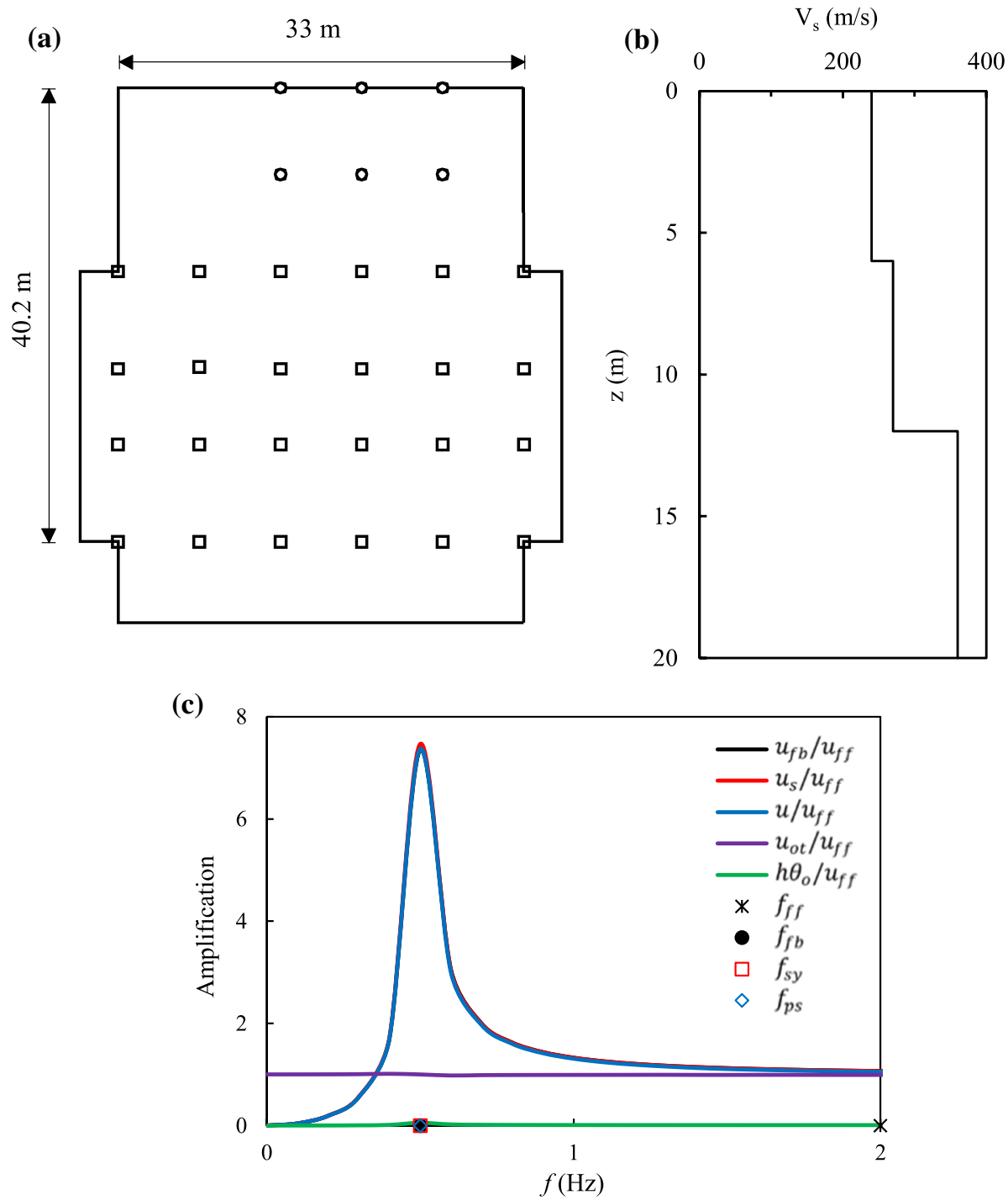

Fig. 11 The Vanir Tower case study 4: a foundation plan (adapted from Stewart and Stewart 1997); b $V_{\mathrm{s}}$ profile; c amplification functions

\subsection{Case study 5: Wadsworth VA Hospital, Los Angeles}

The Wadsworth Veteran Hospital, located in West Los Angeles, consists of 6 stories above the ground surface and a two-level basement, a square base with side of $135 \mathrm{~m}$. The foundation is constituted by 1296 reinforced concrete piles, with $L=15 \mathrm{~m}$ and $d=0.8 \mathrm{~m}$, connected by a thick slab. Pile spacing varies from 3 to 4.5 diameter. The shear wave velocity (Fig. 12a) was established using DH tests in nearby sites having similar geological conditions. 
The building was subjected to the 1994 Northridge earthquake. The maximum ground acceleration in the free-field was $0.25 \mathrm{~g}$. Sensors located at the basement and roof levels recorded peak accelerations of $0.27 \mathrm{~g}$ and $0.36 \mathrm{~g}$, respectively. To account for the strain level induced in the soil by the amplitude of the soil surface motion, the measured shear wave velocity is reduced by a factor of 0.80 within the first $20 \mathrm{~m}$ of depth, and soil damping $\beta_{\mathrm{s}}=8 \%$ assumed.

The theoretical results obtained show important inertial SSI effects (Fig. 12b). The fundamental frequency of the whole system is considerably reduced $\left(f_{\text {sy }}=0.82 \mathrm{~Hz}\right)$ and effective damping increased $\left(\zeta_{\mathrm{sy}}=13.5 \%\right)$ with respect to the fixed-base condition. Base rocking (green line) does not affect the response of the structure, as confirmed by the SIA performed by Stewart and Stewart (1997). The horizontal displacement of the foundation (purple line) appears quite important.

The comparison with the observed effective parameters $\left(f_{\mathrm{sy}}=1 \mathrm{~Hz}, \zeta_{\mathrm{sy}}=9.3 \%\right)$ reported by Stewart et al. (1999b) indicates that SSI is somewhat overestimated. This may be due to the approximate evaluation of the soil stiffness profile.

\subsection{Case study 6: Riverside County Office Building, Indio}

The Riverside County Office Building is formed by four stories above ground level and a single level basement (Fig. 13a). Each column of the structure is founded on a $2 \times 2$ pile group $(s / d=3.25)$. The reinforced concrete tapered piles have length $15 \mathrm{~m}$ and diameter $0.4 \mathrm{~m}$. A thin concrete slab is present across the basement.

The foundation is embedded into the level alluvial terrain of the Indio Hills. Soil conditions at greater depth and the presence of bedrock are not known. The shear wave velocity was estimated using correlations with void ratio. The properties of the soil used in the analysis are reported in Fig. $13 \mathrm{~b}$.

The accelerometric measurements available refer to the 1992 Landers earthquake. The maximum horizontal acceleration at the free-field was $0.086 \mathrm{~g}$. A minor de-amplification $(0.076 \mathrm{~g})$ of the motion at the base relative to the free-field was individuated, whereas a significant amplification $(0.23 \mathrm{~g})$ at the roof resulted.

The steady-state response of the structure shows a small SSI influence (Fig. 13c). The total damping $\zeta_{\text {sy }}$ of the soil-structure system becomes $8.7 \%$ and the fundamental frequency $f_{\text {sy }}=1.40 \mathrm{~Hz}$, which compare well with the empirical results $\zeta_{\text {sy }}=10.3 \%$ and $f_{s y}=1.41 \mathrm{~Hz}$ (Stewart et al., 1999b). No kinematic effects are also observed $\left(E_{\mathrm{p}} / E_{\mathrm{s} 1}=115\right)$.

\subsection{Case study 7: Pacific Park Plaza Tower, Emeryville}

The Pacific Park Plaza Building is a thirty-story reinforced concrete structure, $95.1 \mathrm{~m}$ high, sited in Emeryville (San Francisco). The building is Y-shaped in plan with three wings connected to the central core (Fig. 14a).

Strong motion instrumentation network was installed to study both the response and the dynamic characteristics of the system (Celebi and Safak 1992; Celebi 2001). The foundation consists of a concrete mat of thickness $1.5 \mathrm{~m}$, supported by 828 prestressed concrete friction piles. The piles have length $30 \mathrm{~m}, 350 \mathrm{~mm}$ square cross-section, embedded in a soil deposit of silty sands and silty clays, which extend to a sedimentary bedrock at $150 \mathrm{~m}$ of depth. The site frequency $f_{\mathrm{ff}}$ was estimated to be $0.7 \mathrm{~Hz}$. 
(a)
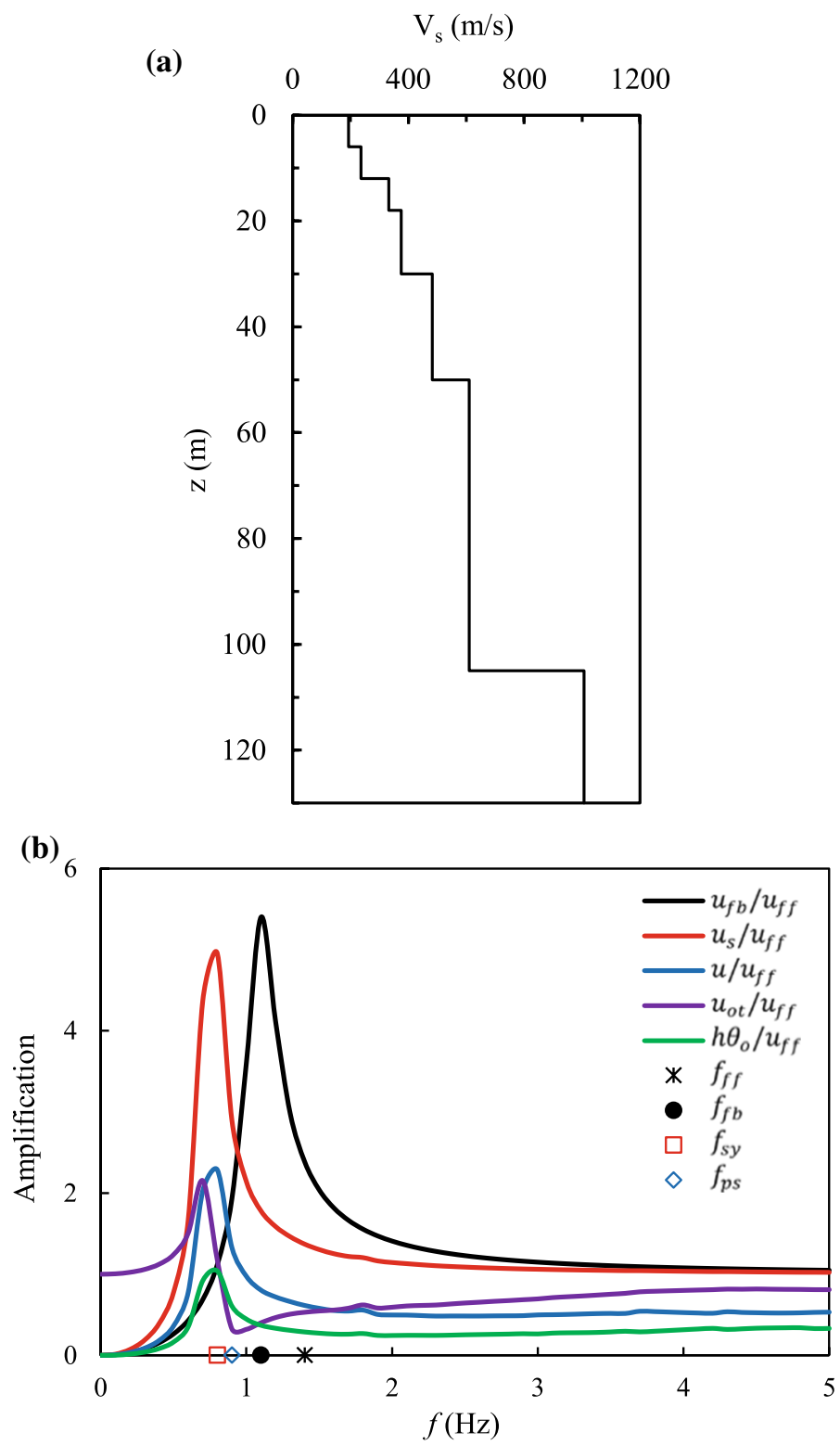

Fig. 12 Case study 5: a shear wave velocity profile (adapted from Stewart and Stewart 1997); b amplification functions

The recorded data refers to the 1989 Loma Prieta earthquake. The maximum freefield horizontal acceleration was $0.26 \mathrm{~g}$. At the ground floor and the roof of the structure the largest peak accelerations exhibited were $0.21 \mathrm{~g}$ and $0.37 \mathrm{~g}$, respectively.

The $V_{\mathrm{s}}$ profile is represented in Fig. 14b. A 0.50 reduction factor for shear wave velocity is used for the softer layers, whereas a factor of 0.80 for the stiffer ones, within 
(a)

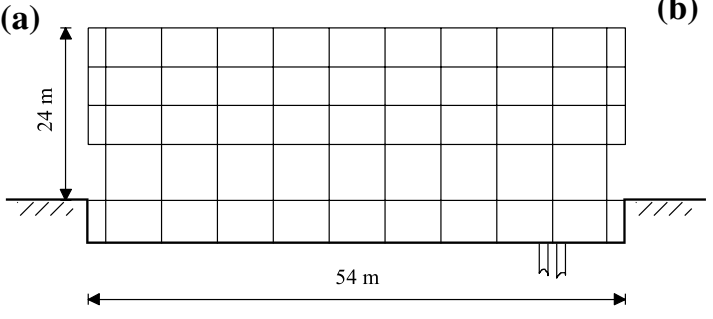

(b)

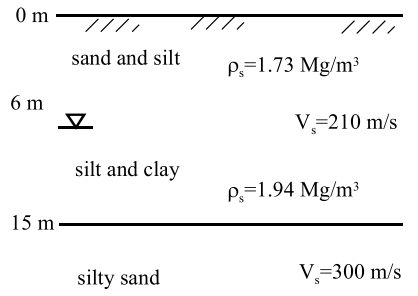

(c)
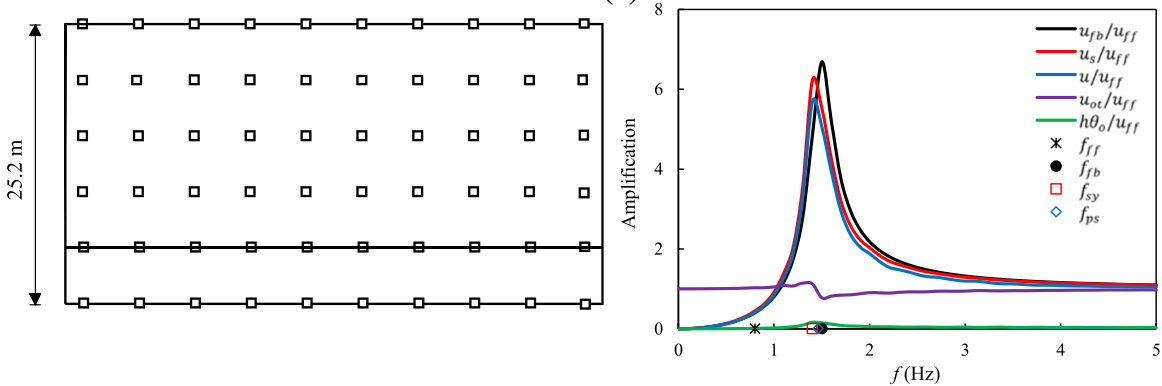

Fig. 13 Case study 6: a elevation and basement plan (adapted from Stewart and Stewart 1997); b soil profile; $\mathbf{c}$ amplification functions

$20 \mathrm{~m}$ depth. Soil damping $\beta_{\mathrm{s}}=8.4 \%$ is adopted. The mass density $\rho_{\mathrm{s}}$ of the soil varies from $1.73 \mathrm{Mg} / \mathrm{m}^{3}$ in the upper layers to $2.04 \mathrm{Mg} / \mathrm{m}^{3}$ at greater depth.

The amplification curves obtained are plotted in Fig. 14c. As can be noticed, a slight interaction between the structure and the surrounding soil is highlighted in terms of period lengthening and effective damping. The vibration frequency $f_{\text {sy }}$ of the entire system is $0.39 \mathrm{~Hz}$, effective damping ratio $\zeta_{\mathrm{sy}}=8.5 \%$. The results of SIA were $f_{\text {sy }}=0.40 \mathrm{~Hz}$ and $\zeta_{\mathrm{sy}}=13 \%$ (Stewart et al. 1999b). The fundamental frequency $f_{\mathrm{ff}}$ of the soil is estimated at $0.6 \mathrm{~Hz}$. The kinematic interaction effects turn out to be negligible $\left(E_{\mathrm{p}} / E_{\mathrm{s} 1}=285\right)$.

\subsection{Case study 8: Administration Building, Long Beach}

The Administration Building in Long Beach is a 7-story steel structure founded on 40 groups of 5 reinforced concrete piles located beneath each column (Fig. 15a). The piles, connected by a slab across the ground floor level, have $L=12 \mathrm{~m}$ and $d=0.4 \mathrm{~m}$. The soil is composed of a silty sand deposit extending to $30 \mathrm{~m}$ of depth. The shear wave velocity (Fig. 15b) was measured by down-hole tests.

The accelerometer recordings refer to the 1987 Whittier earthquake $\left(M_{w}=6\right)$, with a maximum free-field acceleration of $0.07 \mathrm{~g}$. A reduction factor of 0.88 is used for $V_{\mathrm{s}}$.

The steady-state response shown in Fig. 15c indicates a reduction of the resonant response, essentially due to the structural distortion, out of radiation damping $\left(\zeta_{\mathrm{sy}}=8.9 \%, f_{\mathrm{sy}}=0.87 \mathrm{~Hz}\right)$. Minor effects $\left(\zeta_{\mathrm{sy}}=5.5 \%, f_{\mathrm{sy}}=0.89 \mathrm{~Hz}\right)$ were observed by Stewart et al. (1999b). 
(a)

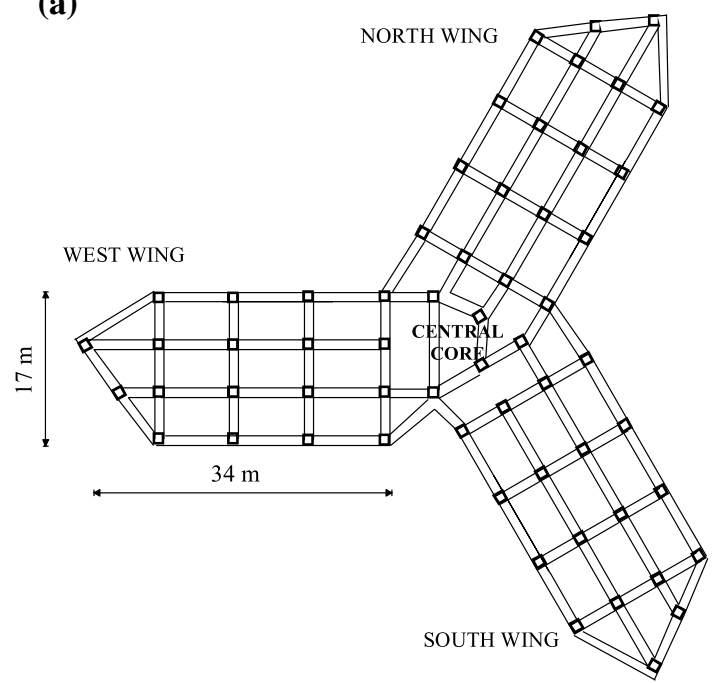

$\mathrm{V}_{\mathrm{s}}(\mathrm{m} / \mathrm{s})$

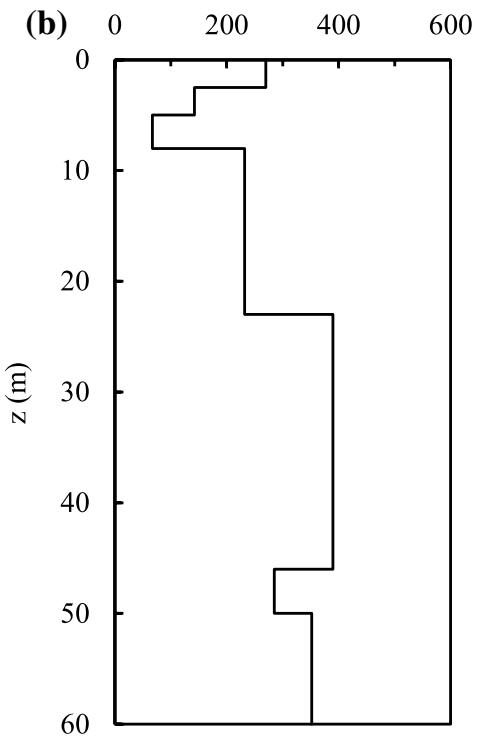

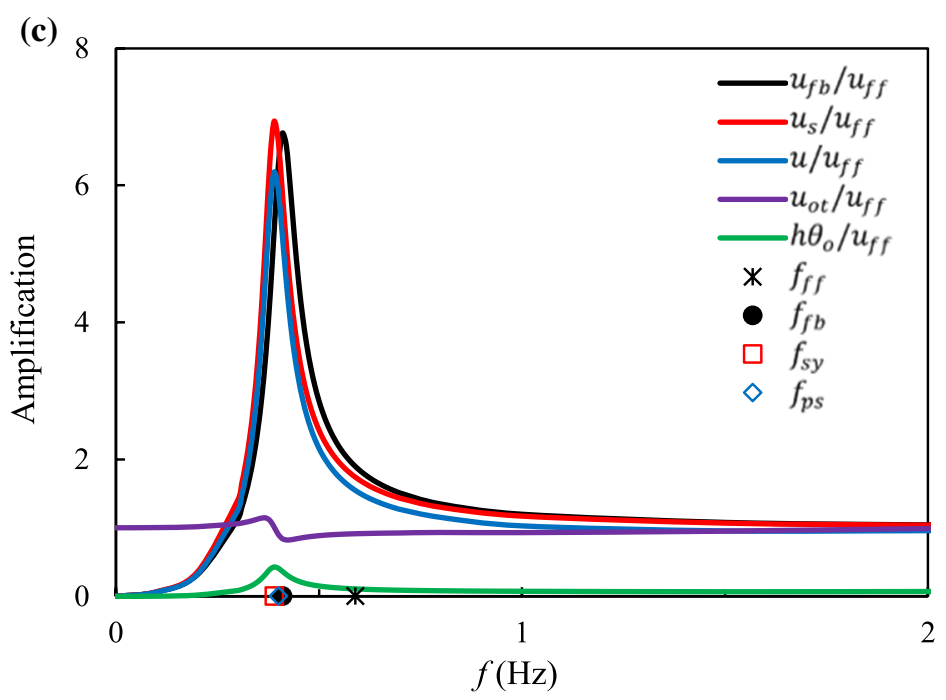

Fig. 14 Case study 7: a ground floor plan (adapted from Stewart and Stewart 1997); b shear wave velocity based on down-hole test; $\mathbf{c}$ amplification functions

\subsection{Case study 9: Avenue of the Stars Building, Los Angeles}

The Avenue of the Stars Building in Los Angeles has 19 stories and rectangular plan (Fig. 16a). The structure is supported by $22 \mathrm{~m}$ long steel I-beam piles installed in groups beneath each column. Pile caps are connected by reinforced concrete tie beams. The soil deposit consists of alternating layers of silt and clay, sand, and clayey silt. The shear wave 


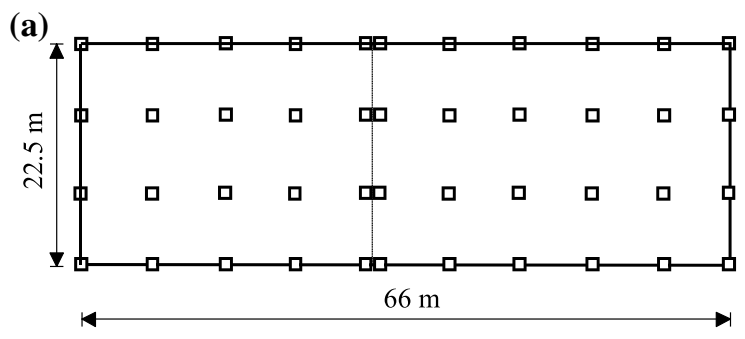

(b)

\begin{tabular}{ccccc}
$\begin{array}{c}\text { depth } \\
(\mathrm{m})\end{array}$ & $\begin{array}{c}\mathrm{V}_{\mathrm{s}} \\
(\mathrm{m} / \mathrm{s})\end{array}$ & $\begin{array}{c}\rho_{\mathrm{s}} \\
\left(\mathrm{Mg} / \mathrm{m}^{3}\right)\end{array}$ & $\begin{array}{c}v_{\mathrm{s}} \\
(-)\end{array}$ & $\begin{array}{c}\beta_{\mathrm{s}} \\
(\%)\end{array}$ \\
\hline $0-18.5$ & 210 & 1.83 & & \\
$18.5-30$ & 330 & 2.04 & & \\
\hline
\end{tabular}

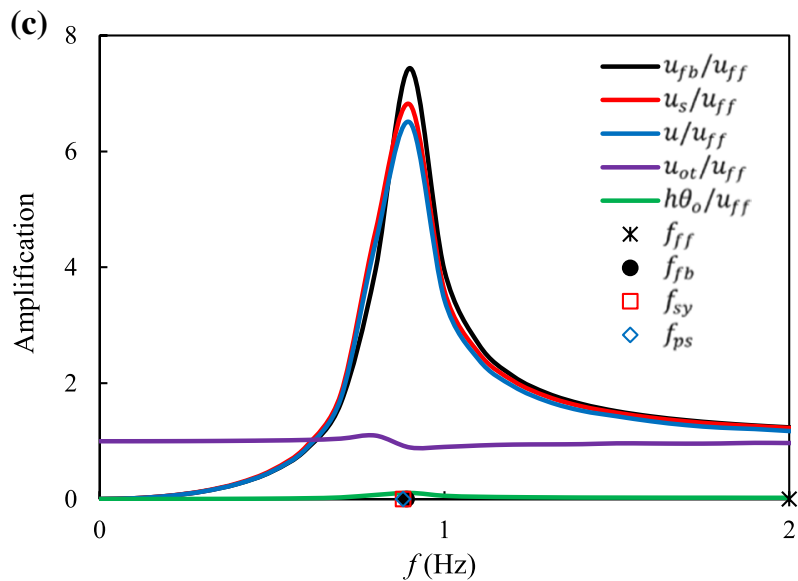

Fig. 15 Case study 8: a foundation plan (adapted from Stewart and Stewart 1997); b soil properties; c amplification functions

velocity profile (Fig. 16b) was established on the basis of down-hole measurements. The 1994 Northridge seismic event was considered in the system identification analysis. The peak ground acceleration in the free-field was $0.28 \mathrm{~g}$. A reduction factor of 0.77 is used for the shear wave velocity of the upper layer, and soil damping $\beta_{\mathrm{s}}=9.2 \%$ is chosen. The damping ratio of the equivalent fixed-base structure is not known.

The amplification functions plotted in Fig. 16c demonstrate that the response of the coupled soil-structure system coincides with the response under fixed-base conditions, as pointed out by the empirical findings (Stewart et al. 1999b). This statement is independent of the structural damping assumed.

\subsection{Case study 10: 47-story Office Building, San Francisco}

The seismic response of a 47-story Office Building (Fig. 17a) sited in San Francisco, subjected to the 1989 Loma Prieta earthquake, is also analyzed. This steel structure is rectangular in plan (Fig. 17b) and has a reinforced concrete mat foundation supported by 150 steel pipe piles infilled with concrete. The piles are $60 \mathrm{~m}$ long and resting on a sandstone bedrock.

No free-field accelerographs were arranged. A maximum acceleration of $0.11 \mathrm{~g}$ was measured at the underground basement level, and a peak response of $0.47 \mathrm{~g}$ was recorded at the roof level. According to Stewart and Stewart (1997), the shear wave velocity of the soil (Fig. 17c) is reduced by a factor of 0.84 and the damping ratio $\beta_{s}$ is set equal to $4.3 \%$. 

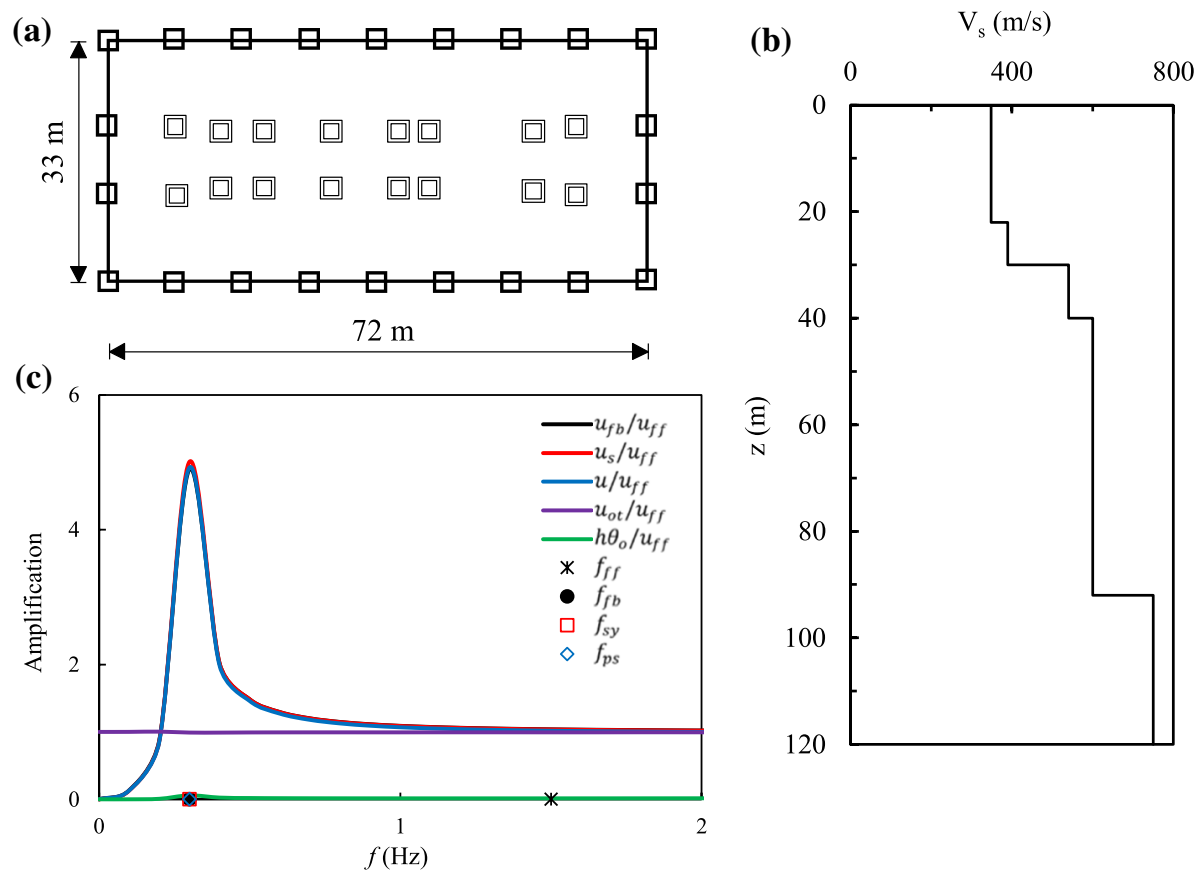

20

Fig. 16 Case study 9: a foundation plan (adapted from Stewart and Stewart 1997); b $V_{\mathrm{s}}$ profile; c amplification functions

The steady-state analysis carried out (Fig. 17d) clearly shows that the fixed-base condition (black line) disregards the beneficial effect of radiation damping (red line). Moreover, it suggests that base rocking (green line) has a small influence on the structural response. Unfortunately, the study conducted by Stewart et al. (1999b) did not report any data about damping.

\subsection{Case study 11: San Bernardino County Services Building, San Bernardino}

The San Bernardino County Government Center is a five-story steel building with an L-shaped plan (Fig. 18a). Groups of 5 piles are placed beneath the columns. The piles have a square section of side $375 \mathrm{~mm}$ and length $10 \mathrm{~m}$. The pile caps are connected by grade beams. The surficial alluvial soil deposit consists of gravely sands and silts, and extends to a depth of about $45 \mathrm{~m}$. Soil properties are reported in Fig. 18b. The shear wave velocity was deduced with empirical correlations.

The strong motion data refer to the 1994 Northridge earthquake. The maximum freefield acceleration recorded was $0.04 \mathrm{~g}$.

The results obtained (Fig. 18c) show that considering the effects of SSI reduces considerably the resonant response $u_{s}$ of the structure, entirely due to its elastic distortion $u$. The fundamental frequency of the system becomes $1.07 \mathrm{~Hz}$, and damping $6.3 \%$. The latter is overestimated with respect to the empirical finding $4.5 \%$ obtained by Stewart et al. (1999b), which found out minor inertial interaction effects between the structure and the supporting soil. 

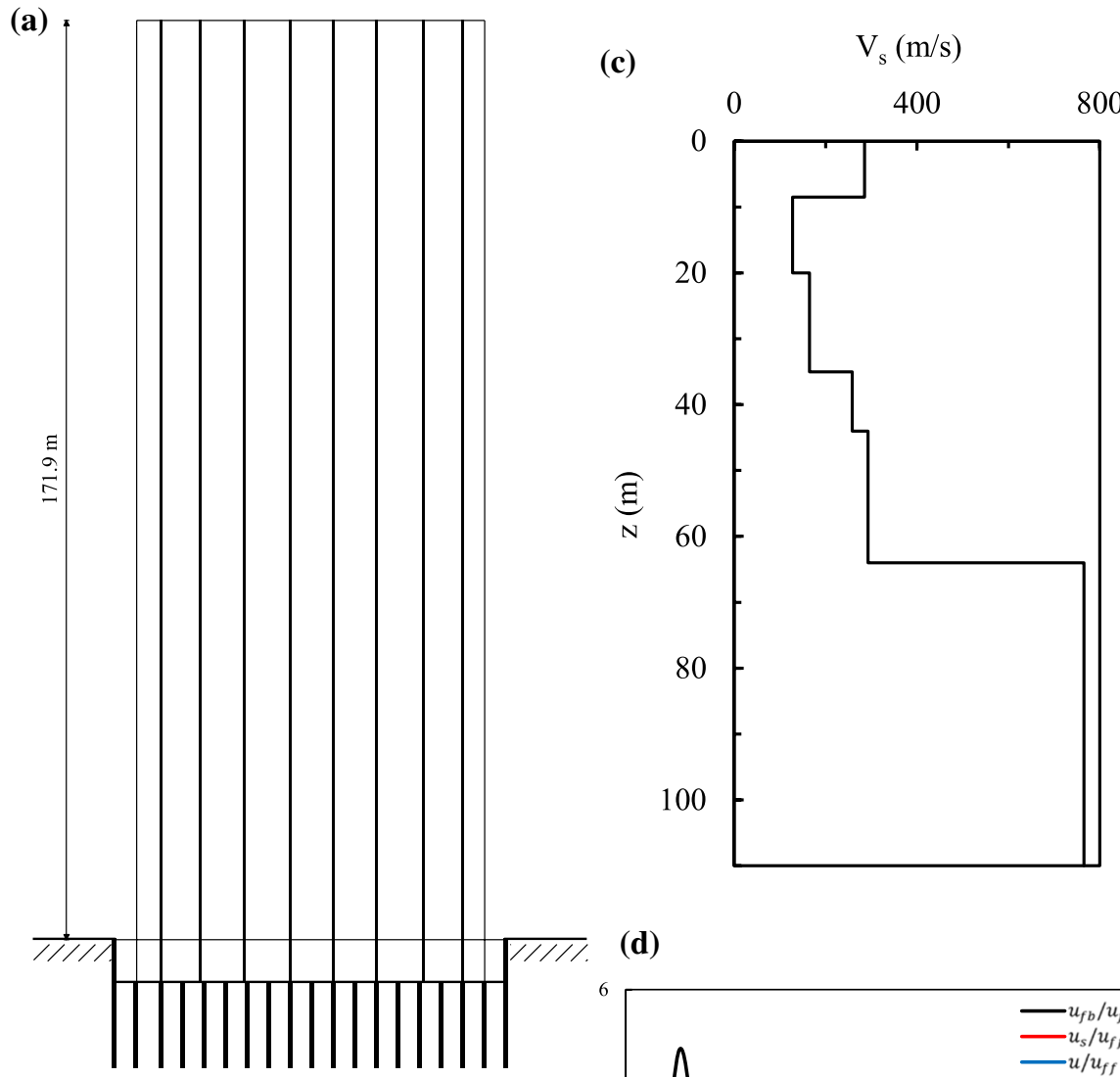

(b)

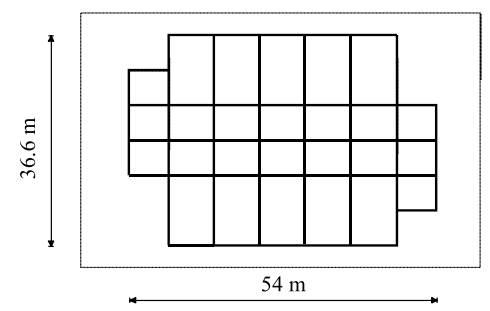

(d)

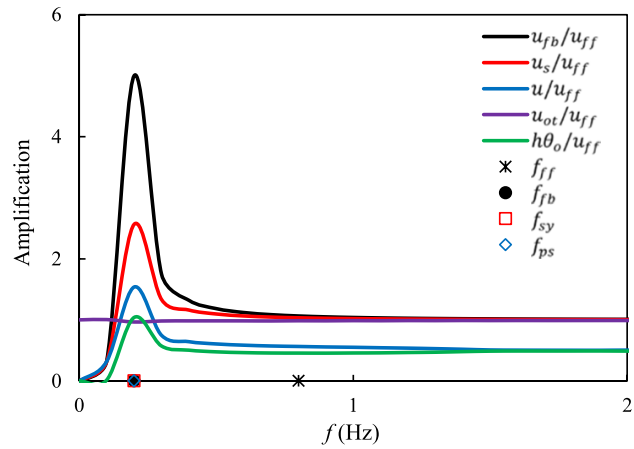

Fig. 17 Case study 10: a building section and b ground floor plan (adapted from Stewart and Stewart 1997); $\mathbf{c}$ shear wave velocity based on down-hole measurements in a nearby site; $\mathbf{d}$ amplification functions

\subsection{Case study 12: Hollywood Storage Building, Los Angeles}

The Hollywood Storage Building is a reinforced concrete structure, 15 stories tall, rectangular in plan (Fig. 19a), founded on concrete piles with length varying from $4 \mathrm{~m}$ at the edge to $9 \mathrm{~m}$ near the center of the construction. The shear wave velocity profile (Fig. 19b) was evaluated based on down-hole measurements. The depth of the bedrock was located at about $120 \mathrm{~m}$. 

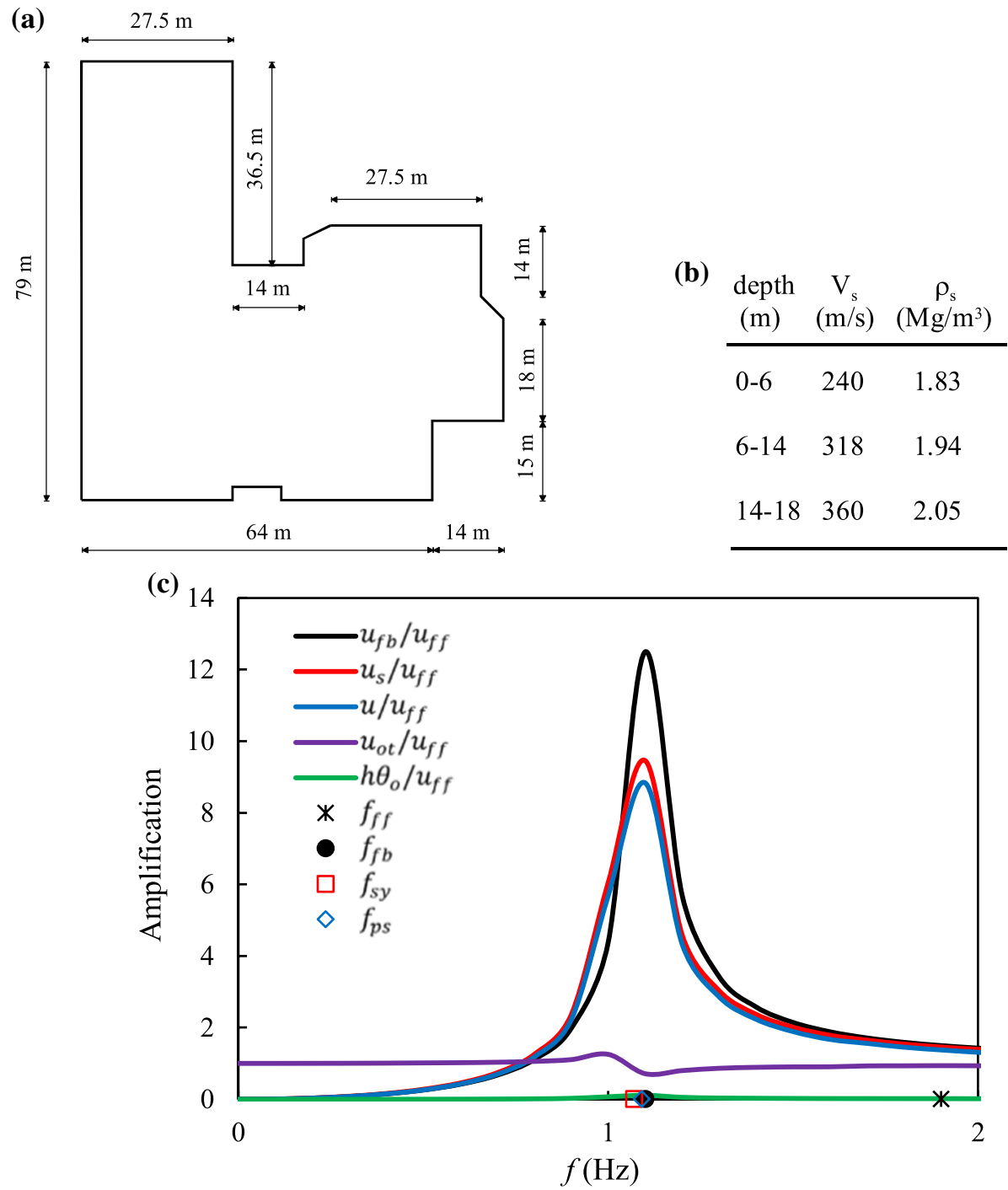

Fig. 18 Case study 11: a ground floor plan (Stewart and Stewart 1997); b soil properties; c amplification functions

The structure was subjected to the 1994 Northridge earthquake and a peak free-field acceleration of $0.39 \mathrm{~g}$ was measured. The fundamental frequency of the soil deposit was estimated to be around $1 \mathrm{~Hz}$.

According to the amplitude of acceleration at the soil surface, the damping of the soil is assumed to be $\beta_{\mathrm{s}}=10 \%$ and the shear wave velocity within the first $20 \mathrm{~m}$ of depth is reduced by a factor of 0.78 .

The frequency response curves are plotted in Fig. 19c. The vibration frequency $f_{\text {sy }}$ of the whole system is equal to $1.25 \mathrm{~Hz}$, and the total damping $\zeta_{\text {sy }}$ calculated with the half-power bandwidth method is $10.3 \%$. The corresponding results obtained by Stewart et al. (1999b) 
(a)

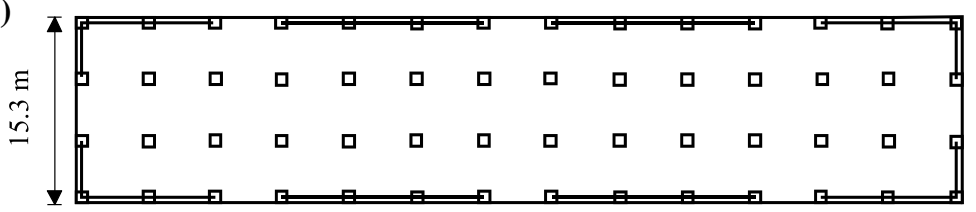

$65.1 \mathrm{~m}$

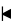

$$
\mathrm{V}_{\mathrm{s}}(\mathrm{m} / \mathrm{s})
$$

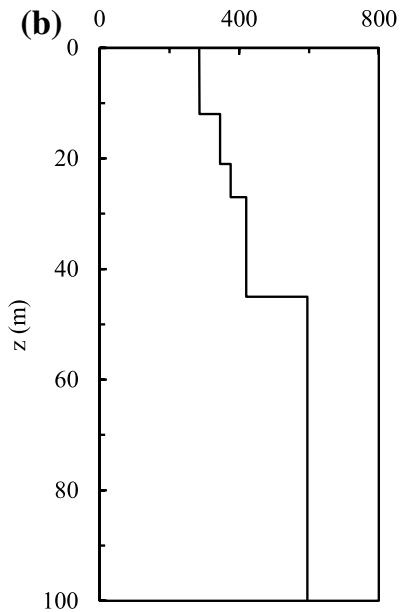

(c)

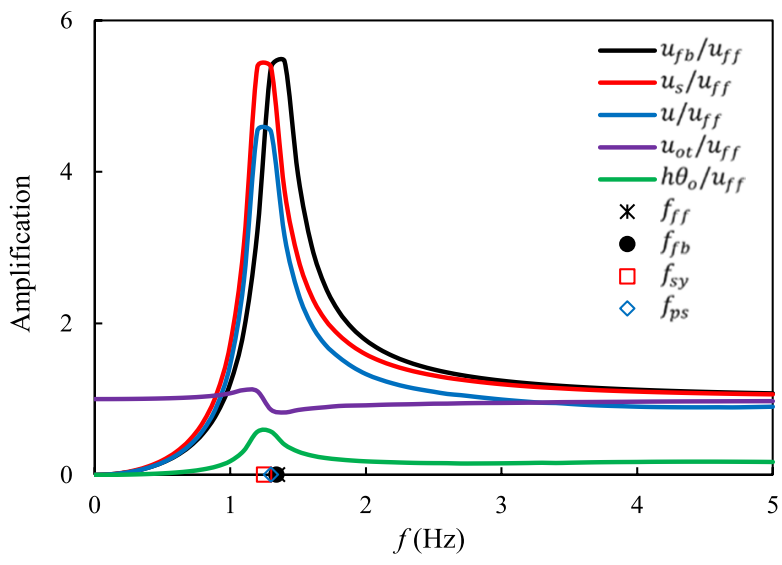

Fig. 19 Case study 12: a foundation plan (adapted from Stewart and Stewart 1997); b $V_{\text {s }}$ profile; c amplification functions

with the system identification analysis were $1.25 \mathrm{~Hz}$ and $8 \%$, respectively. The calculated fundamental frequency of the soil deposit is $f_{\mathrm{ff}}=1.35 \mathrm{~Hz}$. The response of the structure is quite dominated by its flexural displacement $u$, with a modest contribution of base rocking (green line). No kinematic interaction effects are noticed $\left(E_{\mathrm{p}} / E_{\mathrm{s} 1}=85\right)$.

\subsection{Case study 13: 2-story Commercial Building, Pomona}

A reinforced concrete building with 2 stories and a single level basement, sited in Los Angeles County (Pomona) is considered. Its foundation consists of 168 piles having $d=0.6 \mathrm{~m}$ and $L=10 \mathrm{~m}$, installed in groups of 2 and 4 beneath the columns (Fig. 20a).

The soil consists of a sand deposit with occasional gravels and layers of silty fine sand. The shear wave velocity was estimated using correlations with void ratio. A first layer of thickness $6 \mathrm{~m}$ having $V_{\mathrm{s}}=300 \mathrm{~m} / \mathrm{s}$ and a $12 \mathrm{~m}$ thick lower layer with $V_{\mathrm{s}}=450 \mathrm{~m} / \mathrm{s}$ were characterized. Soil conditions at greater depth are not known.

The strong motion processed referred to the 1990 Upland earthquake $\left(M_{w}=5.6\right)$, which generated in the free-field site condition a peak ground acceleration of $0.21 \mathrm{~g}$. The shear wave velocity of the soil is reduced by a factor of 0.84 , and soil damping $\beta_{\mathrm{s}}=6.4 \%$ is assumed.

The harmonic steady-state solutions reported in Fig. 20b highlight the inertial interaction effects (red line): the reduction of the fundamental frequency $\left(f_{\mathrm{sy}}=3.42 \mathrm{~Hz}\right)$ and 
(a)
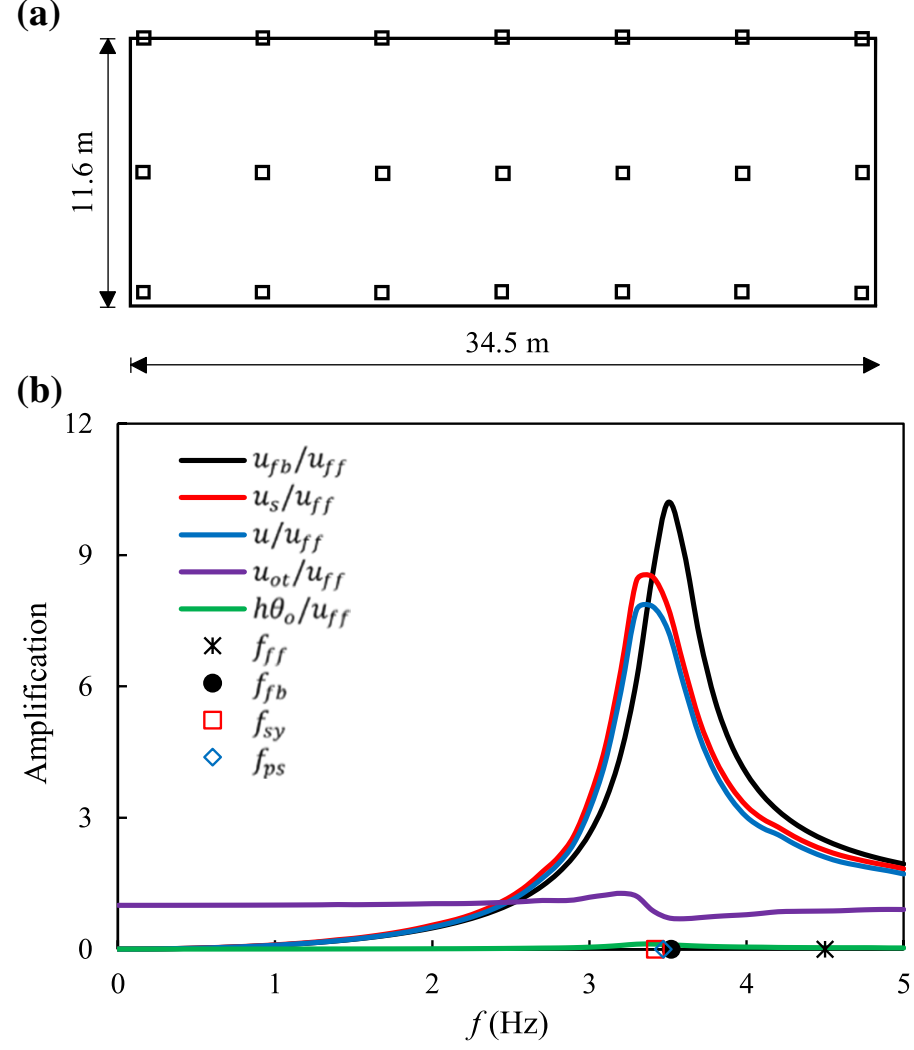

Fig. 20 Case study 13: a foundation plan (adapted from Stewart and Stewart 1997); b amplification functions

the increase of damping $\left(\zeta_{\mathrm{sy}}=6.2 \%\right)$. The observed values obtained by Stewart et al. (1999b) were $3.45 \mathrm{~Hz}$ and $9.2 \%$, respectively. In both researches, no significant deamplification of foundation motion relative to the free-field is noticed $\left(E_{\mathrm{p}} / E_{\mathrm{s} 1}=67\right)$. Besides, base motion (purple and green lines) does not affect the structural response.

\subsection{Case study 14: 7-story Building, Norwalk}

The last case examined deals with a rectangular 7-story steel building (Fig. 21a) located in Norwalk, subjected to the 1987 Whittier earthquake. It is founded on concrete piles varying in length between 8.6 and $11.6 \mathrm{~m}$. Further data are available in Celebi (1993).

The soil deposit is composed of silty, clayey sands and silts. Sandstone bedrock is located at $150 \mathrm{~m}$ of depth. The $V_{\mathrm{s}}$ profile is plotted in Fig. 21b. An average reduction factor 0.82 for $V_{\mathrm{s}}$ and $\beta_{\mathrm{s}}=7.2 \%$ have been assumed according to the recorded peak free-field acceleration of $0.23 \mathrm{~g}$. The results obtained (Fig. 21c) show no SSI effects, as well as the empirical findings substantially confirmed (Stewart et al. 1999b). 
(a)
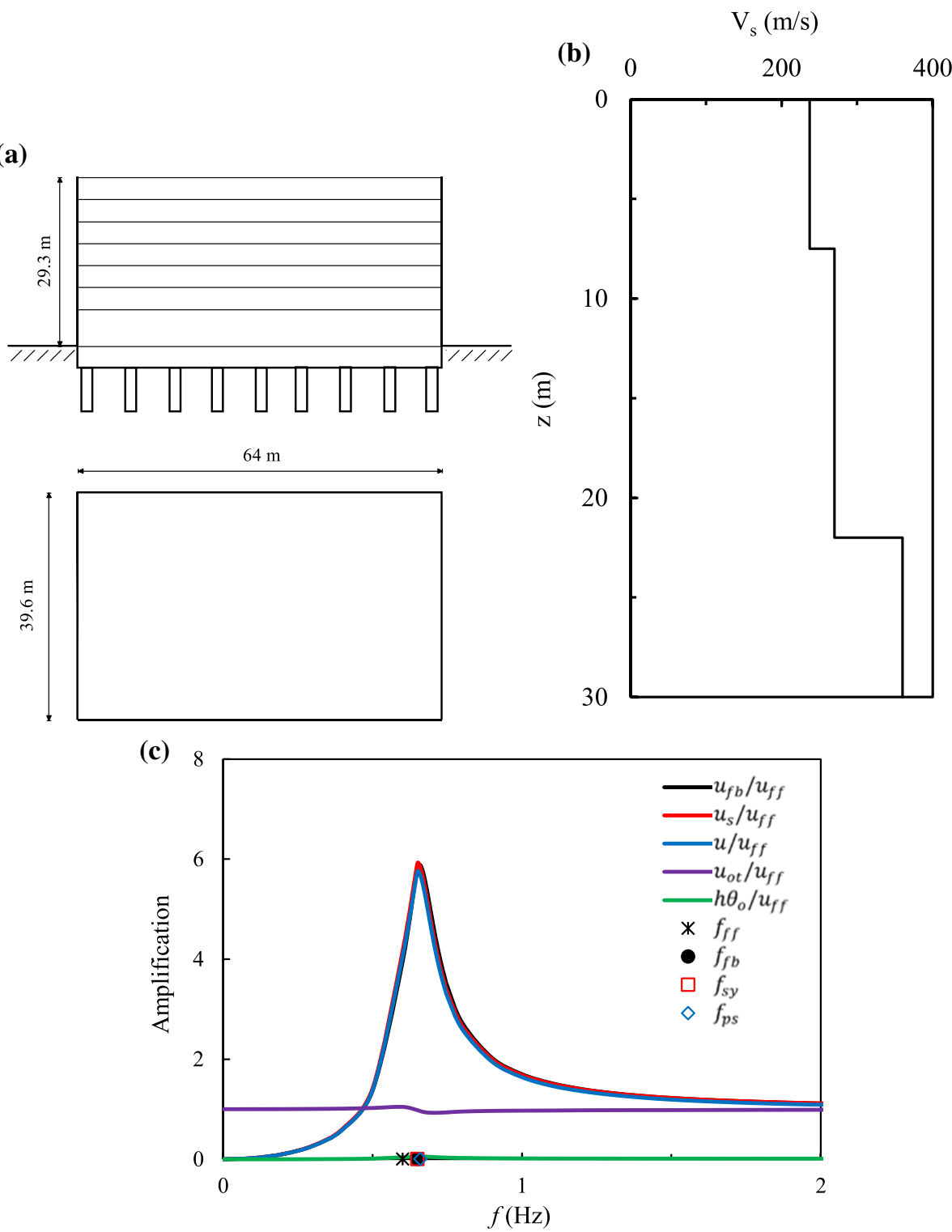

Fig. 21 Case study 14: a section and plan of the structure (adapted from Stewart and Stewart 1997); b soil shear wave velocity; c amplification functions

\subsection{Summary of results}

All the results obtained are synthesized in Table 3 along with the observed flexible-base modal parameters determined from site-specific analyses. 
Table 3 Interaction effects for the case studies examined

\begin{tabular}{|c|c|c|c|c|c|c|}
\hline \multirow[t]{2}{*}{ Case } & \multicolumn{2}{|c|}{$\begin{array}{l}\text { Fixed-base param- } \\
\text { eters } \\
\text { (Stewart et al. } \\
\text { 1999b) }\end{array}$} & \multicolumn{2}{|c|}{$\begin{array}{l}\text { Observed } \\
\text { (Stewart and Stew- } \\
\text { art 1997; } \\
\text { Stewart et al. } \\
\text { 1999b) }\end{array}$} & \multicolumn{2}{|c|}{$\begin{array}{l}\text { Calculated } \\
\text { (present study) }\end{array}$} \\
\hline & $f_{\mathrm{fb}}(\mathrm{Hz})$ & $\zeta(\%)$ & $f_{\text {sy }}(\mathrm{Hz})$ & $\zeta_{\mathrm{sy}}(\%)$ & $f_{\mathrm{sy}}(\mathrm{Hz})$ & $\zeta_{\mathrm{sy}}(\%)$ \\
\hline 1 & 2 & 23.4 & 1.35 & 16 & 1.59 & 17.5 \\
\hline 2 & 3.49 & 18.6 & 2.08 & 6.7 & 2.09 & 8.4 \\
\hline 3 & 1.88 & 5.7 & 1.41 & 4.0 & 1.76 & 6.0 \\
\hline 4 & 0.50 & 6.8 & 0.50 & 7.9 & 0.50 & 7.0 \\
\hline 5 & 1.09 & 9.3 & 1.00 & 9.3 & 0.82 & 13.5 \\
\hline 6 & 1.49 & 7.5 & 1.41 & 10.3 & 1.40 & 8.7 \\
\hline 7 & 0.41 & 7.4 & 0.40 & 13 & 0.39 & 8.5 \\
\hline 8 & 0.88 & 6.5 & 0.89 & 5.5 & 0.87 & 8.9 \\
\hline 9 & 0.29 & - & 0.31 & 8.9 & 0.29 & 10 \\
\hline 10 & 0.20 & - & - & - & 0.20 & 19 \\
\hline 11 & 1.10 & 4.0 & 1.07 & 4.5 & 1.07 & 6.3 \\
\hline 12 & 1.34 & 8.5 & 1.25 & 8.0 & 1.25 & 10.3 \\
\hline 13 & 3.50 & 4.9 & 3.45 & 9.2 & 3.42 & 6.2 \\
\hline 14 & 0.65 & 8.5 & 0.67 & 6.7 & 0.65 & 8.5 \\
\hline
\end{tabular}

11 case studies reveal the presence of inertial interaction effects in terms of reduction of the fundamental frequency of vibration $f_{\text {sy }}$ and/or 'effective' damping $\zeta_{\text {sy }}$ of the coupled soil-structure system.

The theoretical estimates are reasonably good in many cases. A minor accuracy of the present approach with respect to the empirical findings is noticed in the cases 3 and 5 , where shear wave velocity profiles are not given at the specific sites. The same conclusion could be expected for case study 10 , but no observed data are available for the actual structure.

Case studies 6, 7 and 13 show an overall underestimation of the damping, probably due to the lack of information about soil conditions at greater depth. An overpredicted damping is calculated in cases 8 and 11, in which the presence of bedrock was not been established.

The modeling of pile foundations proves quite reliable and permits a good prediction of the fundamental frequency of the soil-structure system.

When peak ground acceleration in the free-field condition is available (Table 1), a reduction factor for $V_{\mathrm{s}}$ and soil damping $\beta_{\mathrm{s}}$ are adopted as a function of PGA, according to the provisions furnished by EC8 (Table 2). In the absence of free-field measurements (cases 2 and 10), the indications provided by Stewart and Stewart (1997) have been assumed. In so doing, nonlinear effects can be considered approximately captured, although in a very simple manner.

Finally, small kinematic interaction effects are found in case study 1, as a relatively high ratio of the pile modulus to the soil Young's modulus is matched (Table 1). 


\section{Conclusions}

In this paper, the main aspects of the soil-structure interaction analysis are considered and discussed with the aid of well-documented case studies. In particular, the influence of pile foundations in the dynamic response of the structure is examined.

Aiming at preserving the clearness and simplicity requested in engineering practice, the study is restricted to the harmonic steady-state solution. The latter permits an easy representation of the peak response of the structure and a fast acquisition of the fundamental parameters featuring the behavior of the soil-structure system under seismic loading. Moreover, use is made of the substructure technique which reveals very attractive for the analysis of large pile groups.

The paper employs a boundary element approach based on the Stiffness Matrix Method, which allows soil heterogeneity to be accounted for in a realistic way. A basic assumption is the validity of the superposition principle, therefore linear soil behavior is mandatory. In order to introduce nonlinear effects, soil stiffness is adequately reduced according to the maximum accelerations recorded at the ground surface in the free-field, and a consistent internal damping is adopted.

In the case examined, the reduced fundamental frequency and the total damping ratio of the soil-structure system are compared with the values observed in the instrumented actual piled-structures. The agreement is found very satisfactory whenever soil stiffness profile was appropriately estimated and nonlinear behavior considered. Finally, the effects of the kinematic interaction prove negligible owing to the small relative pile rigidity and soil layering.

Acknowledgements This study was performed in the framework of the research project ReLUIS 20192021, granted by the Italian Civil Protection Department. The author is grateful to Prof. Jonathan P. Stewart who provided all the essential data for writing the present work.

Author contributions Not applicable.

Funding The authors did not receive support from any organization for the submitted work.

Availability of data and material Data or materials are available from the author.

Code availability Custom code.

\section{Declarations}

Conflicts of interest The author declares no conflict of interest.

Ethical approval Not applicable.

Consent to participate Not applicable.

Consent for publication Not applicable.

Open Access This article is licensed under a Creative Commons Attribution 4.0 International License, which permits use, sharing, adaptation, distribution and reproduction in any medium or format, as long as you give appropriate credit to the original author(s) and the source, provide a link to the Creative Commons licence, and indicate if changes were made. The images or other third party material in this article are included in the article's Creative Commons licence, unless indicated otherwise in a credit line to the material. If material is not included in the article's Creative Commons licence and your intended use is not 
permitted by statutory regulation or exceeds the permitted use, you will need to obtain permission directly from the copyright holder. To view a copy of this licence, visit http://creativecommons.org/licenses/by/4.0/.

\section{References}

Arnold C, Durkin M, Eisner R, Whitaker D (1982) Imperial County Services Building-Occupant behavior as a result of the and operational consequences 1979 Imperial Valley Earthquake. PB83-145532, NSF/ CEE-82050

Banerjee PK, Butterfield R (1981) Boundary element methods in engineering science. Mc-Graw-Hill, UK

Bhatti MA (2005) Fundamental finite element analysis and applications. Wiley, New Jersey

Cairo R, Conte E (2006) Settlement analysis of pile groups in layered soils. Can Geotech J 43(8):788-801. https://doi.org/10.1139/t06-038

Cairo R, Conte E, Dente G (2005) Analysis of pile groups under vertical harmonic vibration. Comput Geotech 32(7):545-554. https://doi.org/10.1016/j.compgeo.2005.10.001

Cairo R, Francese G, Moraca R, Aloe F (2020) Seismic soil-pile-structure interaction. Theoretical results and observations on pile group effects. In: Calvetti $\mathrm{F}$ et al (eds) Geotech research for land protection and development. Springer Nature, Switzerland. https://doi.org/10.1007/978-3-030-21359-6_54

Cairo R, Conte E (2014) L'interazione terreno-struttura nella risposta sismica di ponti con fondazioni profonde (in Italian). In: Convengo Nazionale di Geotecnica, pp 77-93

Cairo R, Conte E, Cosimo VA, Dente G (2009) Analisi dell'interazione cinematica palo-terreno (in Italian). In: XIII Convegno Ingegneria Sismica in Italia, Bologna

Cairo R, Dente G, Dodaro S (2016) Seismic wave effects on the dynamic response of bridge foundations. Int J Bridge Eng special issue:163-184

Celebi M (1993) Seismic response of two adjacent buildings. I: Data and analyses. J Struct Eng 119(8):2461-2476

Celebi M, Safak E (1992) Seismic response of Pacific Park Plaza. I: Data and preliminary analysis. J Struct Eng 18(6): $1547-1565$

Celebi M (2001) Current and new trends in utilization of data from instrumented structures. In: Erdik M et al (eds) Strong motion instrumentation for civil engineering structures. Springer Science, Dordrecht, pp 179-194

Chau KT, Shen CY, Guo X (2009) Nonlinear seismic soil-pile-structure interaction: Shaking table tests and FEM analyses. Soil Dyn Earthq Eng 29:300-310. https://doi.org/10.1016/j.soildyn.2008.02.004

Dobry R (2014) Simplified methods in soil dynamics. Soil Dyn Earthq Eng 61-62:246-268. https://doi.org/10. 1016/j.soildyn.2014.02.008

Dobry R, Gazetas G (1988) Simple method for dynamic stiffness and damping of floating pile groups. Géotechnique 38(4):557-574. https://doi.org/10.1680/geot.1988.38.4.557

Durante MG, Di Sarno L, Mylonakis G, Taylor CA, Simonelli AL (2016) Soil-pile-structure interaction: experimental outcomes from shaking table tests. Earthq Eng Struct Dyn 45(7):1041-1061. https://doi.org/10. 1002/eqe. 2694

EN 1998-5 (2005) Eurocode 8: Design of structures for earthquake resistance. Part 5: Foundations, retaining structures and geotechnical aspects. European Standard EN 1998-5. European Committee for Standardization (CEN), Brussels

Fan K, Gazetas G, Kaynia A, Kausel E, Ahmad S (1991) Kinematic seismic response of single piles and pile groups. J Geotech Eng ASCE 117(12):1860-1879. https://doi.org/10.1061/(ASCE)0733-9410(1991)117: 12(1860)

Gazetas G (1987) Soil dynamics: an overview. In: Banerjee PK, Butterfield R (eds) Dynamic behaviour of foundations and buried structures. Elsevier, London, pp 1-43

Gazetas G, Mylonakis G (1998) Seismic soil-structure interaction: new evidence and emerging issues. Geotech Earthq Eng Soil Dyn III(2):1119-1174

Gazetas G, Fan K, Tazoh T, Shimizu K, Kavvadas M, Makris N (1992) Seismic pile-group-structure interaction. Piles under Dyn Loads, Geotech Spec Publ ASCE 34:56-93

Hokmabadi AS, Fatahi B, Samali B (2014) Assessment of soil-pile-structure interaction influencing seismic response of mid-rise buildings sitting on floating pile foundations. Comput Geotech 55:172-186. https:// doi.org/10.1016/j.compgeo.2013.08.011

Hokmabadi AS, Fatahi B, Samali B (2015) Physical modeling of seismic soil-pile-structure interaction for buildings on soft soils. Int J Geomech ASCE. https://doi.org/10.1061/(ASCE)GM.1943-5622.0000396

Hussien MN, Tobita T, Iai S, Karray M (2016) Soil-pile-structure kinematic and inertial interaction observed in geotechnical centrifuge experiments. Soil Dyn Earthq Eng 89:75-84. https://doi.org/10.1016/j.soildyn. 2016.08.002 
Kausel E (2006) Fundamental solutions in elastodynamics. A compendium. Cambridge University Press, England

Kausel E (2010) Early history of soil-structure interaction. Soil Dyn Earthq Eng 30:822-832. https://doi.org/10. 1016/j.soildyn.2009.11.001

Kausel E (2018) Generalized stiffness matrix method for layered soils. Soil Dyn Earthq Eng 115:663-672. https://doi.org/10.1016/j.soildyn.2018.09.003

Kausel E, Roësset JM (1981) Stiffness matrices for layered soils. Bull Seismol Soc Am 71(6):1743-1761

Kausel E (1981) An explicit solution for the Green functions for dynamic loads in layered media. Research Rep R81-13, MIT

Kim S, Stewart JP (2003) Kinematic soil-structure interaction from strong motion recordings. J Geotech Eng ASCE 129(4):323-335

Kojic S, Trifunac MD, Anderson JC (1993) Earthquake response of the imperial county services building in El Centro. Earthq Eng Eng Vib 13(4):47-72

Maravas A, Mylonakis G, Karabalis DL (2014) Simplified discrete systems for dynamic analysis of structures on footings and piles. Soil Dyn Earthq Eng 61-62:29-39. https://doi.org/10.1016/j.soildyn.2014.01.016

Millan MA, Dominguez J (2009) Simplified BEM/FEM model for dynamic analysis of structures on piles and pile groups in viscoelastic and poroelastic soils. Eng Anal Bound El 33:25-34. https://doi.org/10.1016/j. enganabound.2008.04.003

Mylonakis G, Gazetas G (2000) Seismic soil-structure interaction: beneficial or detrimental? J Earthq Eng 4(3):277-301. https://doi.org/10.1080/13632460009350372

Mylonakis G, Nikolaou S, Gazetas G (2006) Footings under seismic loading: Analysis and design issues with emphasis on bridge foundations. Soil Dyn Earthq Eng 26(9):824-853. https://doi.org/10.1016/j.soildyn. 2005.12.005

NEHRP (2015) Recommended provisions for seismic regulations for new buildings and other structures. FEMA 1050. Building Seismic Safety Council, National Institute of Building Sciences, Washington, DC

NEHRP (2020) Recommended seismic provisions for new buildings and other structures. FEMA P-2082-1. Building Seismic Safety Council, National Institute of Building Sciences, Washington, DC

Nikolaou S, Mylonakis G, Gazetas G, Tazoh T (2001) Kinematic pile bending during earthquakes: analysis and field measurements. Géotechnique 51(5):425-440. https://doi.org/10.1680/geot.2001.51.5.425

Padron LA, Aznarez JJ, Maeso O (2011) 3-D boundary element-finite element method for the dynamic analysis of piled buildings. Eng Anal Bound El 35:465-477. https://doi.org/10.1016/j.enganabound.2010.09.006

Rovithis EN, Pitilakis KD, Mylonakis G (2009) Seismic analysis of coupled soil-pile-structure systems leading to the definition of a pseudo-natural SSI frequency. Soil Dyn Earthq Eng 29(6):1005-1015. https://doi.org/ 10.1016/j.soildyn.2008.11.005

Seybert AF (1981) Estimation of damping from response spectra. J Sound Vib 75(2):199-206. https://doi.org/ 10.1016/0022-460X(81)90339-4

Shepherd R, Plunkett AW (1983) Damage analyses of imperial county services building. J Struct Eng ASCE 109(7):1711-1726

Stewart JP, Fenves GL, Seed RB (1999a) Seismic soil-structure interaction in buildings. I: analytical methods. J Geotech Eng 125(1):26-37

Stewart JP, Fenves GL, Seed RB (1999b) Seismic soil-structure interaction in buildings. II: empirical findings. J Geotech Eng 125(1):38-48

Stewart JP, Stewart AF (1997) Analysis of soil-structure interaction effects on building response from earthquake strong motion recordings at 58 sites. Rep. No. UCB/EERC-97/01, Earthquake Engineering Research Center

Stewart JP, Seed RB, Fenves GL (1998) Empirical evaluation of inertial soil-structure interaction effects. Rep. No. PEER-98/07, Pacific Earthquake Engineering Research Center

Stewart JP, Comartin C, Moehle JP (2004) Implementation of soil-structure interaction models in performance based design procedures. In: Proceedings 3rd UJNR Workshop on soil-structure interaction, Menlo Park, California, USA

Wolf JP (1985) Dynamic soil-structure interaction. Prentice-Hall, Englewood Cliffs, NJ

Publisher's Note Springer Nature remains neutral with regard to jurisdictional claims in published maps and institutional affiliations. 